University of California, Hastings College of the Law UC Hastings Scholarship Repository

Faculty Scholarship

2013

\title{
Clarifying Costs Can Increased Price Transparency Reduce Healthcare Spending?
}

Jaime S. King

UC Hastings College of the Law, kingja@uchastings.edu

Morgan A. Muir

Stephanie A. Alessi

Follow this and additional works at: http://repository.uchastings.edu/faculty_scholarship

\section{Recommended Citation}

Jaime S. King, Morgan A. Muir, and Stephanie A. Alessi, Clarifying Costs Can Increased Price Transparency Reduce Healthcare Spending?, 4 William \& Mary Policy Review 319 (2013).

Available at: http://repository.uchastings.edu/faculty_scholarship/1100

This Article is brought to you for free and open access by UC Hastings Scholarship Repository. It has been accepted for inclusion in Faculty Scholarship by an authorized administrator of UC Hastings Scholarship Repository. For more information, please contact marcusc@uchastings.edu. 


\title{
Clarifying Costs: Can Increased Price Transparency Reduce Healthcare Spending?
}

\author{
Morgan A. Muir,* Stephanie A. Alessi, ** and Jaime S. King***
}

As healthcare expenditures continue to climb, politicians, business leaders, and patients avidly search for new methods to reduce healthcare costs. In an eleven-point plan released in 2012, a group of the nation's top healthcare experts listed "full transparency of prices" as one potential solution to reduce healthcare costs. The experts, some of whom helped write the Patient Protection and Affordable Care Act, argued that price transparency would allow consumers to compare prices before choosing a provider or hospital and, consequently, better anticipate their overall costs. In turn, they argued that making price information publicly accessible would also reduce excess healthcare spending by encouraging providers to offer more competitive pricing.

Other health services research, however, suggests that legislative and regulatory efforts to promote price transparency may result in increased healthcare costs depending on the market conditions and the various stakeholders targeted. Consequently, any price transparency initiative must not only make prices transparent, but also account for the differences between markets, either by reducing the economic inefficiencies that keep price transparency from being effective or by precisely targeting the specific regions where the market would support such an initiative.

This article analyzes whether price transparency initiatives can effectively reduce healthcare costs, and if so, what conditions must exist for them to do so. The features of a welldesigned price transparency initiative will vary depending upon the targeted population (patients, employers, providers, or insurers) and the particular features of the target market. We argue that the most effective solutions will mandate disclosure of price and quality information at the appropriate stakeholder levels and, simultaneously, break down provider market leverage where it prevents price transparency from helping consumers. Together, these two elements have the potential to lower healthcare costs. Finally, we present four possible price transparency initiatives that represent a range of possible alternatives, including litigation, legislation, regulation, and consumer driven initiatives.

\section{TABLE OF CONTENTS}

I. INTRODUCTION .......................................................... 320

II. THE HEALTHCARE MARKET AND PRICE TRANSPARENCY ..................................322

III. CONSUMER-LEVEL PRICE TRANSPARENCY .......................................................323

\footnotetext{
* Research Fellow, UCSF/UC Hastings Consortium on Law, Science and Health Policy; Attorney, Morgan Muir Law.

** J.D., University of California, Hastings College of the Law; Research Fellow, UCSF/UC Hastings Consortium on Law, Science and Health Policy.

${ }_{* * * *}$ Professor of Law, University of California, Hastings College of the Law and Associate Director of the UCSF/UC Hastings Consortium on Law, Science and Health Policy. All authors would like to thank David Faigman, Clay Johnston, Tim Greaney, Ann Marie Marciarille, and Adams Dudley for their thoughtful contributions to earlier drafts of this article.
} 


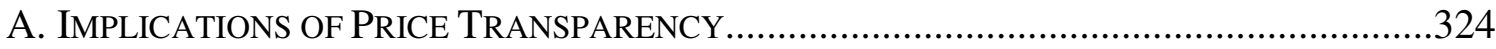

B. BARRIERS TO CONSUMER-LEVEL PRICE TRANSPARENCY ............................................326

IV. INSURER-PROVIDER LEVEL PRICE TRANSPARENCY ........................................327

A. EFFECTS OF PRICE TRANSPARENCY AT THE INSURER-PROVIDER LEVEL.......................327

B. BARRIERS TO INSURER-PROVIDER PRICE TRANSPARENCY ......................................328

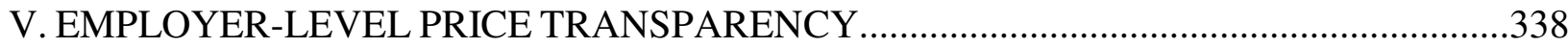

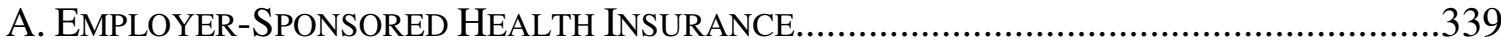

B. BARRIERS TO EMPLOYER-LEVEL PRICE TRANSPARENCY .............................................340

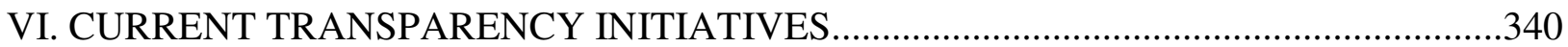

A. CALifornia Laws AND CURRENT TransParency Initiatives .............................341

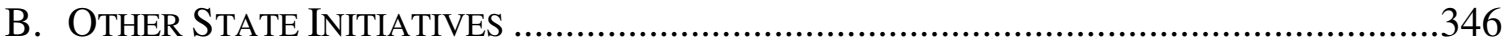

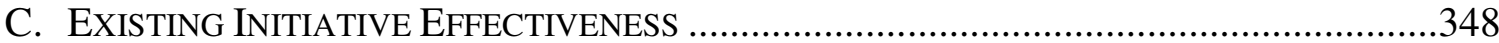

VII. POTENTIAL SOLUTIONS TO PROMOTE EFFECTIVE PRICE TRANSPARENCY...349

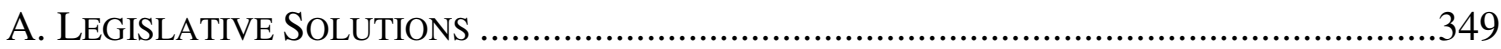

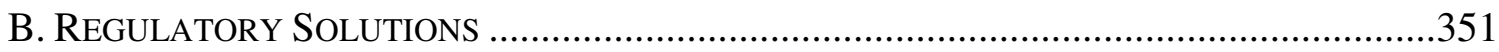

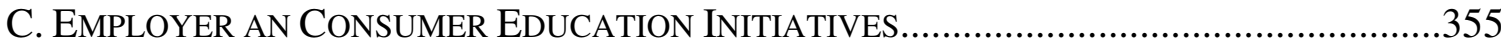

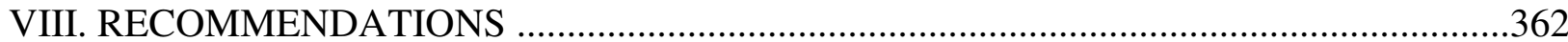

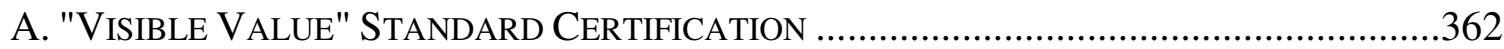

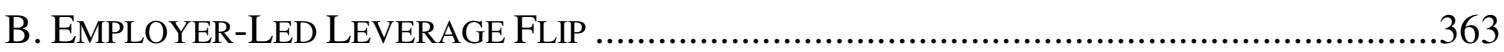

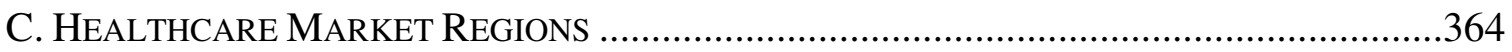

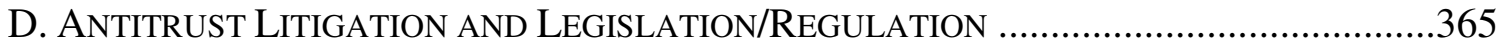

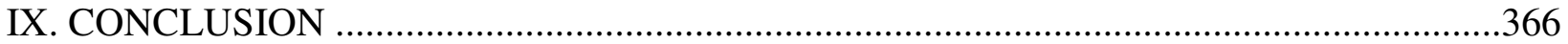

\section{INTRODUCTION}

In 2011, the United States spent \$2.7 trillion dollars on healthcare. ${ }^{4}$ National healthcare expenditures accounted for $17.9 \%$ of the gross domestic product and have nearly doubled since 2000..$^{5}$ In recent years, American businesses have begun to falter under the weight of providing affordable insurance to their employees, and the number of uninsured Americans has increased to over 46 million. ${ }^{6}$ The need to reduce healthcare costs is more apparent than ever and the Affordable Care Act has brought numerous cost-reduction initiatives to the forefront.

In August 2012, several of the nation's top healthcare experts who helped write the Affordable Care Act (ACA) included "price transparency" in an eleven-point plan to reduce health costs. ${ }^{7}$ They argued that price transparency would permit consumers to compare available prices and anticipate overall costs before choosing a provider or hospital. ${ }^{8}$ In turn, publically accessible price information would encourage providers to offer more competitive pricing and

\footnotetext{
${ }^{4}$ CTRS. FOR MEDiCARE AND MEdicAid SERVS., NATIONAl HEAlth EXPENDITUREs 2011 Highlights, available at http://cms.gov/Research-Statistics-Data-and-Systems/Statistics-Trends-and Reports/NationalHealthExpendData/ Downloads/highlights.pdf (last visited February 11, 2013).

${ }^{5} I d$.

${ }^{6}$ Robin A. Cohen \& Michael E. Martinez, Nat'L Ctr. For Health Statistics, CDC, Health Insurance COVERAGE: EARLY RELEASE OF ESTIMATES FROM THE NATIONAL HEALTH INTERVIEW SURVEY, 2011, at 2 (2012) [hereinafter 2011 NATIONAL HEALTH INTERVIEW SURVEY], available at http://www.cdc.gov/nchs/data/nhis/ earlyrelease/insur201206.pdf.

${ }^{7}$ Ezekiel Emanuel et al., A Systemic Approach to Containing Healthcare Spending, NEJM, Aug. 1, 2012, available at http://www.nejm.org/doi/full/10.1056/NEJMsb1205901.

${ }^{8} I d$.
} 
thereby reduce excess healthcare spending, a view consistent with predictions of standard economic theory. ${ }^{9}$

However, whether price transparency will have this effect on the healthcare market remains speculative. Those who believe price transparency alone will reduce healthcare costs assume that the healthcare market will respond like other industries. Economists have long concluded that markets work best when consumer prices reflect the actual cost to create and deliver the product. ${ }^{10}$ In fact, a majority of the empirical studies on price transparency in other markets shows that transparency initiatives tend to lead to more consistent, lower prices. ${ }^{11}$ While similarities exist between healthcare and other consumer markets, some economists believe price transparency will not ameliorate rising healthcare costs due to unique characteristics of the healthcare market. $^{12}$

One major difference is that patient demand for healthcare services generally does not respond in the same manner as consumer demand for other goods in terms of price elasticity, which estimates how consumer demand changes as price changes. ${ }^{13}$ Consumers can delay healthcare due to cost, but once a condition becomes severe or life threatening, consumers will generally seek care regardless of price. This makes the demand for certain healthcare services uniquely inelastic. Price inelasticity in the healthcare market is further exacerbated by the fact that consumers generally learn of their healthcare costs after receiving care, making these costs seemingly unavoidable. In addition, complex billing practices, secretive insurer-provider contracts, the sheer number of third party payers, and major quality variances in delivery of healthcare may mean that it will be difficult for price transparency initiatives to achieve economic efficiency. ${ }^{14}$

Unfortunately, the unique characteristics of this market make analogies and predictions based on other markets less reliable. Each unique quality of the healthcare market is analogous to another market, but no one market contains all of the special characteristics of healthcare. Loosely analogous to corporate managers, who make business decisions that affect the price of stockholders' shares, are providers, who negotiate with insurers over covered treatments and procedure prices and also make recommendations that drive patient demand for the same procedures. Thus, a price transparency initiative that targets consumers alone may be less effective than a multi-faceted one that targets decisions made at the insurer-provider level as well. Similar to the automobile and airline industry, price discrimination can affect healthcare prices when providers charge different payers different prices for identical services, adding to the growing price discrepancies for healthcare within the same geographic region. ${ }^{15}$ Further, third party payers insulate consumers from the full price of healthcare, allowing price to play less of a role in treatment choice than location, physician quality, or other non-price factors.

\footnotetext{
${ }^{9} I d$. at 2-4; see also CRS REPORT FOR CONGRESS: DOES PRICE TRANSPARENCY EFFECT MARKET EFFICIENCY? IMPLICATIONS OF EMPIRICAL EVIDENCE IN OTHER MARKETS FOR THE HEALTHCARE SECTOR (Apr. 29 2008) [hereinafter CRS REPORT FOR CONGRESS].

${ }^{10}$ Robert Murray, Setting Hospital Rates to Control Costs and Boost Quality: The Maryland Experience, 28 HEALTH AFF. 1395, 1397 (2009).

${ }^{11}$ CRS REPORT FOR CONGRESS, supra note 9 , at 9.

${ }^{12} I d$. at 4-5.

${ }^{13}$ Su Liu \& Deborah Chollet, Price and Income Elasticity of the Demand for Health Insurance and Health Care Services: A Critical Review of the Literature-Final Report, Mathematica Policy Research, Inc. (Mar. 24, 2006).

${ }^{14}$ CRS REPORT FOR CONGRESS, supra note 9 , at 5 .

${ }^{15}$ Uwe E. Reinhardt, The Price of U.S. Hospital Services: Chaos Behind A Veil of Secrecy, 25 HeALth AfF. 57, 58 (2006).
} 
Over 30 states are currently considering or pursuing legislation to increase price transparency. ${ }^{16}$ To date, most transparency initiatives have targeted consumers. However, initiatives targeting the insurers, providers, and employers may prove more effective. This article analyzes the current debate about price transparency in the healthcare market and the role that law and policy play in the implementation of price transparency initiatives to lower the cost of healthcare. The analyses herein will critique existing price transparency initiatives and examine ideas for new initiatives that may benefit the healthcare market today.

Part II provides information on the healthcare market as it relates to price transparency and presents different potential price transparency intervention points. Parts III, IV, and V examine initiatives directed at these intervention points - the consumer, insurer-provider, and the employer levels, respectively - in more depth. For each intervention point, the article analyzes the potentially substantial legal barriers and other obstacles to price transparency. Part VI examines current transparency legislative initiatives across the country - with a special focus on California - as well as the potential for regulation from the Health Benefit Exchanges. Part VII then analyzes a range of possible price transparency initiatives aimed to effectively target each specific intervention point, including consumer and employer education, antitrust litigation, state legislation, and state agency regulation. These potential solutions serve as a framework for analyzing price transparency initiatives, accounting for varying healthcare market conditions, differences in legislation and regulations on price transparency across the country, and the range of market barriers and legal hurdles discussed in each Part.

Lastly, based on the analysis in Part VII, Part VIII recommends four possible legal, regulatory, and educational solutions that might be taken alone or in combination to form an effective price transparency initiative. By offering several potential solutions to simultaneously reduce anticompetitive behavior in healthcare markets and make price and quality information available in a meaningful way, these proposals provide healthcare consumers a viable path toward fair and visible prices. ${ }^{17}$

\section{THE HEALTHCARE MARKET AND PRICE TRANSPARENCY}

According to the Centers for Disease Control and Prevention (CDC) National Center for Health Statistics (NCHS), an estimated 46.3 million persons of all ages $(15.1 \%$ of the United States population) were uninsured in $2011 .^{18}$ Sixty-four percent of insured persons were covered by private health insurance plans $-82.1 \%$ of those persons obtained employer-based coverage, while $15.3 \%$ purchased their plan independently of their employers. ${ }^{19}$

The price of healthcare goods and services carries a different meaning depending on the targeted party. Whereas co-pays and monthly premiums matter most to individual consumers, healthcare providers are most affected by reimbursement rates paid by private and public health

\footnotetext{
${ }^{16}$ Anna D. Sinaiko \& Meredith B. Rosenthal, Increased Price Transparency in Healthcare-Challenges and Potential Effects, 364 New Eng. J. Med. 891, 891 (2011).

${ }^{17}$ While the analyses and recommendations provided herein use California as the target case study, many of the issues also pertain to markets in other states across the country.

${ }^{18}$ Robin A. COHEN \& Michael E. MartineZ, NAT'L CTR. FOR Health STATistics, CDC, Health Insurance COVERAGE: EARLY RELEASE OF ESTIMATES FROM THE NATIONAL HEALTH INTERVIEW SURVEY, 2011, at 2 (2012) [hereinafter 2011 NATIONAL HEALTH INTERVIEW SURVEY], available at http://www.cdc.gov/nchs/data/nhis/ earlyrelease/insur201206.pdf.

${ }^{19}$ U.S. Census Bureau, CuRrent Population SuRvey, ANNuAl Social ANd ECONOMic SupPlement (2012), available at $\mathrm{http}: / / \mathrm{www} . c e n s u s . g o v / \mathrm{cps} / \mathrm{data} / \mathrm{cpstablecreator.html.}$
} 
insurers. Therefore, revealing certain healthcare costs to the wrong party will not be as useful or as effective in lowering healthcare costs as a more appropriately targeted approach.

Insurers, providers, employers, and individual consumers are all potential targets for price transparency initiatives. Price information aimed at facilitating competition between providers or insurers differs from information aimed at providing guidance to consumers. To illustrate these potential points of intervention for transparency initiatives, consider the following example of an MRI: Provider A's gross charge for an MRI is $\$ 2,000 .^{20}$ However this is not the price an insurer pays, or the price for which the insured consumer is responsible. For this MRI, Provider A has negotiated a rate of $\$ 1,000$ with Insurer $X$ and a rate of $\$ 1,500$ with Insurer $Y$, but Patient B will pay a copay of $\$ 50$ with Insurer $X$ or a $10 \%$ co-insurance of $\$ 150$ with Insurer $Y$.

The effect of any particular price transparency initiative will depend significantly on the targeted entities, the relevant market conditions, the usefulness of the information disclosed, and the ability of the targeted entity to act on that information. A well-designed price transparency initiative that takes into account these factors can reduce healthcare costs, while others will have little effect, or worse, could increase healthcare costs.

The following sections demonstrate different price disclosures at each of the consumer, insurer-provider and employer levels, and their impact.

\section{CONSUMER- LEVEL PRICE TRANSPARENCY}

The goal of consumer-level price transparency is to create better-informed consumers of healthcare. $^{21}$ The hope is that well-informed consumers will use easily accessible and comprehensible price and quality information to purchase lower-priced, higher-quality healthcare, thereby changing market demand and lowering overall prices. Consumers of healthcare include both individual persons and employers who purchase healthcare benefits for employees. This section focuses on the individual consumer, while Part IV tackles the issues surrounding employer-level price transparency. Consumer-directed price transparency initiatives can mandate disclosure of prices at two points: 1) individuals at the point of plan selection; and 2) individuals at the point of provider/treatment selection. While many existing consumer-level transparency initiatives target individuals, these initiatives have had only moderate levels of success because patients do not have access to complete price and quality information in an easily comprehensible and usable format. ${ }^{22}$

Price transparency at the individual consumer level concerns the amount of payment for which the consumer is responsible. For uninsured consumers, the price of care is also the same as the total payment to the provider. However, for insured consumers the price they pay for care often represents only a small fraction of the overall cost; the insurance plan will pay for the rest, often at negotiated and discounted rates. Prior to selecting a health plan, individuals typically receive information on the different pricing structures associated with various insurance companies. Access to meaningful price and quality comparison data would enable consumers to carefully evaluate health plans before becoming a customer. Historically, at the point of plan selection, consumers have had access to plan premiums, deductible, and coinsurance amounts.

\footnotetext{
${ }^{20}$ The gross charge for a medical procedure is the price billed to uninsured consumers. This amount is often different from the actual price recovered by providers.

${ }^{21} I d$. at 894.

22 JH Hibbard \& E Peters, Supporting Informed Consumer Health Care Decisions: Data Presentation Approaches That Facilitate the Use of Information in Choice, 24 ANnUAL Rev. Pub. HeAlth 413 , 414-16.
} 
However, as more individuals move into high deductible health plans (HDHPs), consumers will have to pay the actual prices of specific services out of pocket, making provider costs also relevant to plan selection. Once enrolled in a health plan, consumers will require additional information regarding the price tiering of providers within their chosen plan, such as whether certain providers will require a higher level of coinsurance or copay. Price transparency initiatives targeting individual consumers should offer access to provider reimbursement rates that, along with provider quality information, can assist consumers in plan and provider selection. Unfortunately, providing meaningful price and quality information in a usable format for individual consumers has proven very challenging. Attempts to do so have resulted in only marginal consumer uptake. ${ }^{23}$

\section{A. IMPLICATIONS OF CONSUMER-LEVEL PRICE TRANSPARENCY}

Economists and health policy scholars have debated the effects of transparency on the healthcare market for years. ${ }^{24}$ While traditional economic theory argues that access to meaningful information in any market will result in a decrease in product cost, ${ }^{25}$ others caution that, in the healthcare market, price transparency may result in unintentional effects, including price increases, if not implemented properly. ${ }^{26}$ This Part describes these different theoretical effects and considers the reasoning behind each in order to better craft an economically efficient initiative.

In 2008, Congress commissioned the Congressional Research Service (CRS) to examine the effect of greater price transparency on the healthcare market. ${ }^{27}$ The CRS ultimately concluded that greater price transparency might lead to lower prices. ${ }^{28}$ In preparing the Report, CRS examined several empirical studies on price transparency in other markets and several economists' opinions on what these studies predict for the healthcare market. Generally, the Report concluded that if the healthcare market reacts to price transparency in the same way as other markets, then increasing the transparency of price information available to consumers will improve competition and drive down prices. ${ }^{29}$ On the other hand, because of the special characteristics of healthcare, the Report also warns that increasing price transparency may increase prices in certain situations. ${ }^{30}$

Michelle Kim, a PhD in healthcare management and economics, also uses economic theory to examine the effect of transparency measures on the healthcare market. ${ }^{31}$ Her

\footnotetext{
${ }^{23}$ CRS Report for Congress, supra note 9.

${ }^{24}$ See, e.g., JH Hibbard, J Stockard, and M Tusler, "Does publicizing hospital performance stimulate quality improvement efforts?, HEALTH AFFAIRS, 2003; 22(2): 84-94 (demonstrating that the debate about transparency in the healthcare market goes back at least a decade).

${ }^{25}$ Cutler \& Dafny, supra note 36, at 894.

${ }^{26}$ Id. at 894; see also Sinaiko \& Rosenthal, supra note 16, at 892.

${ }^{27}$ CRS Report for Congress, supra note 9.

${ }^{28}$ Id. at 33-4.

${ }^{29}$ CRS REPORT FOR CONGRESS, supra note 9, at 39 (citing Per Baltzer Overgaard, Market Transparency, Information Exchange and Competition, presented at the workshop on Competition Strategies and Competition Law, Swedish School of Economics and Business Administration, Helsinki, Oct. 14, 2003, available at http://mit.econ.au.dk/vip_htm/povergaard/pbohome/webpapers/transpcomphelsinki.pdf).

${ }^{30}$ CRS REPORT FOR CONGRESS, supra note 9, at 38 (citing Morten Hviid \& H. Peter Møllgaard, Univ. of Copenhagen, Dep't of Econ., Countervailing Power and Price Transparency (Ctr. for Competition \& Regulation, Working Paper CCR 01-2, 2001) (arguing when less informed buyers can observe prices negotiated by more informed buyers, sellers are less willing to offer lower prices to the informed buyers)).

${ }^{31}$ Michelle Kim, The Effect of Hospital Price Transparency in Healthcare Markets (2011) (Ph.D. dissertation in Health Care Management and Economics, University of Pennsylvania).
} 
dissertation focused on the clearinghouse model for transparency. This model focuses on the effects of consumers who have access to a list of prices charged by different sellers in a market, and assumes that "informed" consumers with access to such a list will choose the lower-cost products, whereas "uninformed" consumers without access will purchase products in the market at random. ${ }^{32}$ Kim reports the effect of healthcare price transparency on (1) market share, (2) market efficiency, and (3) price sensitivity among medical care consumers. ${ }^{33}$ In terms of market share, Kim states that if more informed consumers search for the lowest priced providers, the market will experience a shift in consumers away from fee-for-service plans. ${ }^{34}$ However, Kim notes the difficulty of providing price and quality information to consumers in one central location, as opposed to piecemeal reporting of quality information on one website and price on another. ${ }^{35}$ Without quality information available in the same location as price information, Kim suggests that consumers will be unable to choose lower-priced providers. ${ }^{36}$ Instead, consumers will continue to equate cost with quality, likely causing prices to remain constant, if not increase. ${ }^{37}$ Kim's results for consumer price sensitivity suggest that increased price transparency in a cost sharing system will lead to a reduction in healthcare expenditures, but only if it is possible to provide cost and quality information together so that consumers can understand the true value of services before receiving them. ${ }^{38}$

At the consumer level, many empirical studies of consumer-directed transparency initiatives have reported little to no effect on healthcare prices. ${ }^{39}$ If these consumer-targeted initiatives have any hope of affecting the healthcare market, it will be essential to link quality to price and to present consumers with this information in a useful and easily digestible format. Otherwise, an initiative could have no effect-or worse, increase costs through collusion, for example. ${ }^{40}$

To avoid the potential for an increase in healthcare costs, David Cutler and Leemore Dafny argue that disclosing more limited price information, such as average provider reimbursement rates instead of complete cost information, may make price cuts to certain insurers less detectable, collusion efforts more difficult, and prices less likely to rise. ${ }^{41}$ But, while the disclosure of average prices reduces price secrecy, such limited disclosures will not be sufficient to also affect patient healthcare decisions. In practice, average prices can depict such an expansive range that consumers are often unable to draw helpful price comparisons among providers. Further, limited disclosure cannot capture the many variables that affect price variation - including condition severity, geographic location, and quality of provider - that will inevitably affect price. ${ }^{42}$

While research on the effects of price transparency often generates mixed predictions and unknown results, one consistent conclusion prevails: Making price information publicly

\footnotetext{
${ }^{32}$ Id. at 16.

${ }^{33} \mathrm{Id}$. at $61-69$.

${ }^{34} \mathrm{Id}$. at 12 .

${ }^{35}$ Id. at 30.

${ }^{36} \mathrm{Id}$. at 68 .

${ }^{37}$ Id. at $128-29$.

${ }^{38} I d$. at 66 . Note that Kim's study used charges billed and not actual out-of-pocket costs.

${ }^{39}$ See, e.g., supra Part V.A.1.

${ }^{40}$ See, e.g., supra Part III.A, discussing the potential for increased costs due to price transparency at the insurerprovider level.

${ }^{41}$ Cutler \& Dafny, supra note 36 , at 895.

${ }^{42}$ The limitations of average price disclosure are discussed in more detail in Part IV.B.
} 
available must be done with extreme care in order to begin to shape healthcare decision-making and avoid unwanted price increases.

\section{B. BARRIERS TO CONSUMER-LEVEL PRICE TRANSPARENCY}

Unfortunately, even well thought-out price transparency initiatives face significant barriers to success. At the consumer level, trade secrets protections, contractual barriers, general provider resistance, the question of whether consumers will seek out available price information, and complex cost-shifting and complex billing practices in the healthcare market create hurdles to achieving price transparency that must be cleared before implementing a successful initiative. Trade secret protections, contractual barriers, and provider resistance will be addressed in the following section. This section on consumer based-initiatives will address consumer usage, and complex cost-shifting and billing practices.

\section{QUESTIONABLE CONSUMER USAGE}

Even if a health policy initiative were successfully enacted, many health policy experts warn that consumers may not use this information in the ways previously described. ${ }^{43}$ If consumers will not comparison-shop for their healthcare like they do for other consumer products, making healthcare prices readily available to consumers will have very limited effects on healthcare spending. ${ }^{44}$

Major changes in healthcare billing practices may need to occur before transparency aimed at consumers can be expected to drive down the cost of healthcare. ${ }^{45}$ Uwe Reinhardt, Professor of Political Economy and Economics at Princeton University in the area of health policy, has argued that consumer-directed reforms cannot positively impact the healthcare industry unless hospital billing practices are reformed to allow consumers to readily understand how and for what services they will be charged. ${ }^{46}$ The current chaotic system of hospital pricing would, if made completely transparent to the public, be akin to "forcing sick and anxious people to shop around blindfolded for cost-effective care." vary more than prices negotiated with providers, regulating hospital pricing structures should be a priority. ${ }^{48}$ Effective consumer-directed price transparency will require translating the complicated language of healthcare billing into easy-to-understand information if consumers are expected to utilize that information in their decision-making. ${ }^{49}$

Even if hospital prices became more user-friendly and readily available, consumers may not use it when making decisions about where to receive treatment and from whom. Health services research demonstrates that patients are more likely to base treatment decisions on the experiences of friends and family members than cost. ${ }^{50}$ Further, in the absence of accessible and comprehensible quality information on providers, patients may inaccurately equate lower prices with lower quality services, defeating the purpose of price transparency.

\footnotetext{
${ }^{43}$ GAO REPORT ON PRICE TRANSPARENCY, supra note 67 (citing CRS REPORT FOR CONGRESS, supra note 9); Ginsburg, supra note 73, at 211 (stating consumers will not use information they do not understand).

${ }^{44}$ GAO REPORT ON PRICE TRANSPARENCY, supra note 67 (citing CRS REPORT FOR CONGRESS, supra note 9); Ginsburg, supra note 73, at 211 (stating consumers will not use information they do not understand).

${ }^{45}$ Reinhardt, supra note 15; see also infra Part IV.A.1.

${ }^{46}$ Reinhardt, supra note 15.

${ }^{47}$ Id. at 68 .

${ }^{48}$ Ginsburg, supra note 73 , at 213

${ }^{49}$ See CATALYST FOR PAYMENT REFORM, supra note 35, at 1-2.

${ }^{50}$ Anna D. Sinaiko, How Do Quality Information and Cost Affect Patient Choice of Provider in a Tiered Network Setting? Results from a Survey, Health Serv Res. 2011 Apr: 46(2):437-56, 451; see also Henry J. Kaiser Family Foundation, National Survey on Americans as Health Care Consumers: An Update on the Role of Quality Information, (Menlo Park, Calif.: Kaiser Family Foundation, 2000).
} 
Ultimately, a consumer-directed initiative alone cannot change the course of healthcare spending. In the right circumstances, initiatives aimed at increasing transparency of prices at the provider-insurer level are more likely to reduce costs. Therefore, whether consumers become more informed purchasers of healthcare as a result of a price transparency initiative is not dispositive of the effectiveness of price transparency overall. However, a consumer-targeted initiative may be a helpful piece of a larger price transparency strategy, so long as consumers are able to understand and effectively use price information in their decision-making processes.

\section{COMPLEX COST-SHIFTING AND BILLING PRACTICES}

Complicated healthcare billing practices also pose additional challenges to the implementation of effective consumer-based price transparency measures. The complex series of cost-shifts in the healthcare industry-from the insurer, through multiple providers, to the consumer-also contributes to potential difficulties for individual consumers and employers in obtaining complete price information. ${ }^{51}$ For hospital procedures, both in- and out-patient services, the billing passes through multiple providers, e.g., the anesthesiologist, surgeon, and the hospital. Provider networks can minimize some complexity, as insurers have access to innetwork prices in advance based on their contractual relationship with those providers. But as soon as a patient sees one out-of-network provider in the chain, estimating costs in advance becomes more problematic.

Questions of consumer usage and complex billing practices must be addressed as part of launching an effective consumer-based price transparency initiative. However, before consumers can access the information, numerous barriers must be overcome to obtain price information from insurers and providers. Each presents a formidable challenge to implementing effective price transparency initiatives and will be discussed in further detail in Part IV.

\section{INSURER-PROVIDER LEVEL PRICE TRANSPARENCY}

Between insurers and providers, numerous legal and practical mechanisms prevent disclosure of negotiated price terms that hinder price transparency. Currently, confidentiality clauses and so-called "gag clauses" in provider-insurer contracts ensure that knowledge of negotiated prices stay between the parties in privity of contract. ${ }^{52}$ Insurers and providers may also seek to protect the confidentiality of their prices as a trade secret. Lastly, providers may simply resist any price transparency initiative that may compromise their bottom line. As a result, third party insurers, providers and consumers are kept in the dark as to the prices being charged and collected.

Using the illustration introduced above, Provider A charges Insurer $\mathrm{X}$ a lower rate than it charges Insurer Y. However, because the contract price terms between Provider A and Insurer X are protected by a gag clause, Insurer $\mathrm{Y}$ is unable to use those price terms to negotiate a lower rate with Provider A. Mandating price transparency of negotiated rates at the insurer-provider level may facilitate more competitive pricing by allowing Insurer Y to use its knowledge of the contract with Insurer $\mathrm{X}$ to negotiate a lower rate. This would, in theory, drive down overall healthcare costs as competitors would be able to use their knowledge of these prices to increase their bargaining leverage and negotiate for lower prices.

A. EFFECTS OF PRICE TRANSPARENCY AT THE INSURER-PROVIDER LEVEL

However, theory may not always turn into practice. Unlike its conclusions on the effects of consumer-level price transparency, CRS warned that, because of the special characteristics of

\footnotetext{
${ }^{51}$ CRS REPORT FOR CONGRESS, supra note 9, at 8-12.

${ }^{52}$ See infra Part IV.A.
} 
healthcare, increasing price transparency might increase prices at the insurer-provider level. ${ }^{53}$ For instance, the same report on the effects of consumer-level price transparency highlights the effects of price transparency on the airline industry, which, like the hospital industry, has high fixed costs and a non-storable product. ${ }^{54}$ After the Airline Deregulation Act of 1978, increased competition led to lower fares for consumers and lower salaries for many employees. The most valuable components of the industry, however, such as pilots and mechanics, like highly specialized surgeons in healthcare, did not experience a salary reduction. ${ }^{55}$ The Report concluded that well-designed price transparency initiatives, however, could improve efficiency, while permitting innovative and highly valued providers to remain highly compensated. ${ }^{56}$ However, pilots do not have a similar ability to stimulate demand for their services in the way that surgeons do, which can continue to lead to higher overall costs.

Cutler and Dafny similarly analogize to other markets in order to analyze the potential effects of price transparency on the healthcare market. ${ }^{57}$ Their article on increased price transparency looks to the Danish ready-mix concrete industry in the early 1990s, where Danish authorities implemented a price transparency policy against suspected anticompetitive practices by publishing actual invoice prices. ${ }^{58}$ Within one year from the dissemination of that information, average prices in the industry rose 15 to $20 \% .{ }^{59}$ The most likely explanation for the price increase is that publishing transaction prices quickly revealed competitor price cuts, which made it easier for ready-mix concrete firms to avoid competition. ${ }^{60}$

Given the varied hypotheses and dearth of actual studies, the effect of price transparency on the healthcare market remains largely uncertain. It seems at least possible that some price transparency initiatives could lower healthcare costs in certain markets, but this may be merely one piece to the larger transparency puzzle. Initiatives targeted at providing greater transparency between insurers and providers could, on one hand, inspire providers to raise prices to a uniform or near uniform level. On the other hand, transparency at the provider-insurer level could empower insurers to negotiate for lower prices, which would contribute to an overall decrease in healthcare prices. For a transparency initiative at the insurer-provider to have a chance to lower healthcare costs, it must first overcome certain legal obstacles that currently keep price data concealed.

\section{B. BARRIERS TO INSURER-PROVIDER PRICE TRANSPARENCY}

At the insurer-provider level, confidentiality clauses, or "gag clauses," in provider-insurer contracts prevent consumers and competing providers from knowing negotiated provider rates. Second, to oppose mandated price transparency or prohibitions on gag clauses, providers and

\footnotetext{
${ }^{53}$ CRS REPORT FOR CONGRESS, supra note 9, at 38 (citing Morten Hviid \& H. Peter Møllgaard, Univ. of Copenhagen, Dep't of Econ., Countervailing Power and Price Transparency (Ctr. for Competition \& Regulation, Working Paper CCR 01-2, 2001) (arguing when less informed buyers can observe prices negotiated by more informed buyers, sellers are less willing to offer lower prices to the informed buyers)).

${ }^{54}$ CRS REPORT FOR CONGRESS, supra note 9, at 33.

${ }^{55} \mathrm{Id}$.

${ }^{56} \mathrm{Id}$.

${ }^{57}$ Cutler \& Dafny, supra note 36.

${ }^{58}$ Id. at 895; see also CRS REPORT FOR CONGRESS, supra note 9, at 31, 38-39; STEPHEN MARTIN, Chapter 3 : Collusion and Tacit Collusion, in InduSTRIAl OrganizATION: A EuropeAn PERSPECTIVE 49, 56-57 (2001).

${ }^{59}$ MARTIN, supra note 53, at 56-57 (stating that it is not possible to explain the price increase in terms of demand factors because "[d]uring this period, there was no particular boom in the construction industry, the major user of ready-mix concrete"); see also CRS REPORT FOR CONGRESS, supra note 9, at 31, 38-39.

${ }^{60}$ MARTIN, supra note 53, at 57.
} 
insurers may also allege trade secret protection of negotiated prices to prevent disclosure of that information.

\section{CONTRACTUAL BARRIERS}

Contract terms can prevent disclosure of negotiated rates to anyone outside of the contracting parties. ${ }^{61}$ This section addresses the barriers to price transparency created by confidentiality clauses, also called "gag clauses," and most-favored-nation (MFN) clauses. Gag clauses in contracts between insurance companies and providers currently constitute a significant barrier to third party disclosure of much of the relevant healthcare pricing information. ${ }^{62}$ These gag clauses between hospitals and manufacturers of healthcare devices can even keep physicians from knowing true price information about the technology they use every day, ${ }^{63}$ leaving some providers without an incentive to contain costs by reducing unnecessary tests and treatments. ${ }^{64}$ An MFN clause, on the other hand, is a contractual agreement that prohibits a provider from giving any other insurer a deeper discount than the contracting insurer. Both gag clauses and MFN clauses can thwart transparency efforts and have the effect of unnecessarily raising consumer costs.

\section{a. Gag Clauses}

While some existing price transparency initiatives circumvent these contractual obligations by disclosing cost ranges or gross prices, such figures are not specific enough to be useful for consumers or employers in making purchasing decisions. More specific price information, however, is often subject to "gag clauses" in contracts between insurers and providers that prohibit the contracting parties from disclosing the negotiated prices with third parties. These gag clauses allow insurers to pay "must-have" providers, or anchor providersthat is, essential providers to a health plan-higher than market prices for services, without other providers' knowledge. ${ }^{65}$ Further, they prevent payers and consumers from knowing the differences in provider-negotiated rates. Without the ability to compare prices, providers, payers, and consumers cannot be sure they are getting a competitive price. Price transparency initiatives to eliminate gag clauses at the insurer-provider level would allow other insurers and providers, who are not parties to the contract, to know the prices their competitors charge or are being charged for specific services.

Gag clause prohibitions can produce varied effects depending upon specific market dynamics. In markets with high levels of competition, eliminating gag clauses might give insurers more incentives and leverage, if consumers gravitate toward low-cost, high-quality providers. Under those circumstances, providers will not be able to insist on higher rates unless they have the cost and quality measures to support that demand. However, this model assumes that, in highly competitive healthcare markets, cost and quality information is available, easilyaccessible, and that patients will use it to make healthcare decisions. To date, no data is available to support this assumption. Even worse, in markets without substantial competition,

\footnotetext{
${ }^{61}$ Gov'T AcCountability OfFice, GAO-11-791, 15 Health CARe Price Transparency: Meaningful Price INFORMATION IS DIFFICULT FOR CONSUMERS TO OBTAIN PRIOR TO RECEIVING CARE 1 (2011) [hereinafter GAO REPORT ON PRICE TRANSPARENCY].

${ }^{62}$ Jeffrey C. Lerner et al., The Consequences of Secret Prices: The Politics of Physician Preference Items, 27 HEALTH AFF. 1560, 1561 (2008).

${ }^{63}$ Gov't ACCOUnTability OfFice, GAO-12-126, Medicare: Lack OF PRICE Transparency May Hamper Hospitals' Ability to Be Prudent PURChasers of IMPLANTABle Medical DeVices 29-31 (2012).

${ }^{64}$ SHANNON BROWNLEE, OVERTREATED: Why TOO MUCH MEDICINE IS MAKING Us SicKER AND POORER 28-42 (2008).

${ }^{65}$ Berenson et al., supra note 24, at 973.
} 
transparency of prices paid to "must-have" providers may encourage other providers with as good or better quality measures to demand even higher prices, thereby driving up the cost of healthcare in those markets.

Efforts to eliminate gag clauses that target provider and insurer behaviors can translate into lower or higher costs overall. At best, providers might be forced to provide valuable, transparent reasons for charging higher prices, such as quality measures or being the only provider in a healthcare market who offers certain services, or else lower their prices to maintain a profitable patient base. At worst, this might allow competing providers to demand higher prices, driving up costs. ${ }^{66}$ Market concentration and the negotiating power of providers must be addressed before price transparency can truly be effective. But identifying this possibility, and the market conditions that create it, can enable policymakers to design around this concern.

Unfortunately, successful price transparency initiatives to remove gag clauses may prove more elusive when aimed at affecting consumer choice. Unlike insurers and providers who may have a more complete understanding of codes and healthcare pricing structures, consumers on the whole do not and cannot effectively use information they do not understand. ${ }^{67}$ In order for disclosure of insurer-provider negotiated prices and quality information to consumers to help lower healthcare costs, the information must be easily accessible and comprehensible, not simply available. $^{68}$

Just as transparency interventions aimed at the insurer-provider level may result in a benefit to consumers by creating lower prices, consumer-level disclosure may, in turn, affect providers and insurers by allowing consumers to demonstrate where their demand lies, thereby creating a more level playing-field for contract negotiations. Returning to the MRI cost example from Part II, a price transparency initiative eliminating the gag clause in the contract between Provider $\mathrm{A}$ and Insurer $\mathrm{X}$ can create these mutually beneficial results. First, Insurer $\mathrm{Y}$ would gain access to the $\$ 1,000$ rate between Provider $A$ and Insurer $X$. This would give Insurer $Y$ increased bargaining leverage and allow it to negotiate for a lower rate. Second, eliminating the gag clause would allow individual consumers and employers to comparison shop between Insurer $\mathrm{X}$ and Insurer $\mathrm{Y}$. In choosing the insurer with the lowest reimbursement rate, Insurer X, consumers have the ability to increase the demand for Insurer $X$ 's rate. This would also give Insurer Y more leverage at the bargaining table to negotiate for a lower rate. Both levels of price transparency, therefore, have the potential to drive down healthcare costs.

While disposing of gag clauses may prevent secret deals and selective discounts that lead to escalating costs, some economists believe that price transparency at the provider-payer level could have the opposite effect of actually raising prices charged to patients. Thus, thorough economic analysis of the effects of this type of initiative in different market settings is necessary.

b. Most-Favored-Nation Clauses

Most-favored-nation (MFN) clauses have also had similar effect on the healthcare market, stifling competition and driving up healthcare costs. ${ }^{69}$ In the healthcare market, MFN clauses occur most often when large insurers with substantial market power agree to pay "must-

\footnotetext{
${ }^{66}$ See supra Part II.

${ }^{67}$ Paul B. Ginsburg, Market Watch: Shopping for Price in Medical Care, HeALTH AFF. WEB EXCLUSIVE, Feb. 6, 2007, at 208, 211 (citing Hibbard \& Peters, supra note 38).

${ }^{68}$ Kaiser Family Found., Transparency \& Complexity (Aug. 13, 2012), http://policyinsights.kff.org/en/2012/august/ transparency-and-complexity.aspx (stating that while simplified assumptions make it easier for health plans to produce coverage illustrations, mis-estimating costs make the price information must less useful to consumers because the effect on the plan differences is masked).

${ }^{69}$ Cutler \& Dafny, supra note 36, at 894-95.
} 
have" providers a higher than fair price to have them in their network. These agreements can have the effect of setting a minimum price for all medical services covered by the contract. "Thus, the cost of such services incurred by a dominant insurer with an MFN clause can become the minimum price for all other competitors in the market that deal with those same providers., ${ }^{, 70}$ As a result, MFN clauses can make it impossible for new insurers to offer a competitive plan in a given market because of the inability to negotiate the same or lower prices with "must-have" providers. $^{71}$

To have a competitive advantage, an insurer must ensure that it pays the lowest price for important providers, not that it pays a low price. As a result, large insurers do not need to use their leverage to negotiate lower costs and can accommodate higher price demands from providers. Any additional costs can be passed on to consumers in the form of higher premiums. In the healthcare market, the existence of MFN clauses in insurer-provider contracts has hindered alternative delivery systems and interfered with competition, causing prices to rise. ${ }^{72}$ Like initiatives to prevent MFN clauses, price transparency initiatives would enable large insurers to negotiate to obtain the lowest prices applicable to a "must-have" group of providers. However, this might cause must-have providers to charge higher prices overall, rather than lowering them. Further, price transparency initiatives would also allow competitor providers to see the higher prices other providers have been able to negotiate and demand to be paid those prices as well, which could drive up the cost of healthcare across the board. However, without price transparency, certain markets may fall prey to great insurer bargaining power. Insurers could continue to offer certain providers lower rates and better camouflage costs, perpetuating arbitrary rates rather than rates that are competitively-driven.

Contractual barriers, in the form of gag clauses and MFN clauses, inhibit efforts to increase healthcare price transparency. These barriers exist in large part due to market concentration and increased provider leverage, which in turn can be used to hinder competition and drive up insurance premiums. ${ }^{73}$ However, at this stage, economists can only speculate as to the current impact of these clauses on healthcare prices and the effects of prohibiting them on the future of the healthcare market. Greater economic analysis of healthcare market conditions and behavior must be conducted before complete price transparency can be implemented by the prohibition of confidentiality clauses.

\section{TRADE SECRET BARRIERS: PRICE INFORMATION AS TRADE SECRETS}

Confidentiality clauses and agreements in contracts also raise the question of whether healthcare prices-that is, the negotiated rates in insurer-provider/hospital contracts-are trade secrets, such that insurers could defend against the mandatory disclosure of a price transparency initiative.

Trade secret law is determined on a state-by-state basis. To date, 46 states have adopted the Uniform Trade Secrets Act (UTSA). ${ }^{74}$ The UTSA was intended to codify section 757 of the

\footnotetext{
${ }^{70}$ James F. Doherty \& Monique Ras, Most Favored Nation Clauses in Payor/Provider Agreements, at 3, available at http://www.insurance.ohio.gov/documents/MFN6.pdf.

${ }_{71}^{71}$ Cutler \& Dafny, supra note 36, at 894.

${ }^{72} I d$. at 895.

${ }^{73}$ See, e.g., Thomas L. Greaney, Accountable Care Organizations - The Fork in the Road, 364 NEw ENG. J. OF MED. E1, E2 (2011); Thomas L. Greaney, Accountable Care Organizations - A New Thing with Some Old Problems, 3 Health L. OUtLOOK, 6, 9 (2010).

${ }^{74}$ James H. Pooley et al., \$ 1.2 in Overview of California Trade Secrets Law, in Trade Secrets Practice in California , CEB ONLAw (2d ed. 2011). States that have not adopted the UTSA rely on common law based on the Restatement of Torts.
} 
First Restatement of Torts, ${ }^{75}$ which defines a trade secret as including "not simply information as to single or ephemeral events in the conduct of the business . . . [but] a process or device for continuous use in the operation of the business." At common law under Section 757, the "continuous use" requirement effectively excludes ephemeral events, such as specific sales price information, from protection. The UTSA, however, eliminated the continuous use requirement. This change, arguably, may broaden the definition of what kinds of information can be afforded trade secret protection, so as to include pricing information. ${ }^{76}$ The inclusion of price information, however, ultimately remains uncertain in the healthcare market because it has yet to be resolved by the courts.

The threshold question in trade secret law must be whether the information is a trade secret. Usually the answer is determined when the holder of an alleged trade secret files a misappropriation claim, alleging that someone or some entity has used or disclosed their trade secret information through improper means. ${ }^{77}$ If the information is determined to be a trade secret, that information is protected only against misappropriation. If no trade secret exists, an alleged misappropriator is not liable under the state's UTSA, even if the information was improperly acquired.

In terms of possible healthcare price transparency mandates, the analysis will not focus on whether price information has been misappropriated; before such mandates are in place, no misappropriation can occur. Rather, this analysis must preempt a misappropriation claim and examine whether a transparency initiative can force insurers and providers to disclose their pricing information without running afoul of their legal ability to protect their alleged trade secrets. This will depend upon whether pricing information meets the definition of a trade secret.

\section{DEFINING PRICE INFORMATION AS A TRADE SECRET}

The 1984 Uniform Trade Secrets Act defines a trade secret as follows:

'Trade secret' means information, including a formula, pattern, compilation, program, device, method, technique, or process that: (1)

Derives independent economic value, actual or potential, from not being

generally known to the public or to other person who can obtain economic

value from its disclosure or use; and (2) Is the subject of efforts that are

reasonable under the circumstances to maintain its secrecy. ${ }^{78}$

Whether information is a trade secret is a question of fact $;{ }^{79}$ the court will objectively determine whether a trade secret exists. A party's belief that information is secret or contractually confidential may be a factor in the analysis, but is not dispositive. ${ }^{80}$

a. First Prong - Unknown information with economic value

\footnotetext{
75 Commissioners' Comment to Uniform Trade Secrets Act \$1, in TRADE SECRETS: A STATE-BY-STATE SURVEY 986 (Brian M. Malsberger ed., 1st ed. 1997) (stating that the purpose of the Act is to "codif[y] the basic principles of common law trade secret protection").

${ }^{76}$ Annemarie Bridy, Trade Secret Prices and High-Tech Devices: How Medical Device Manufacturers Are Seeking to Sustain Profits by Propertizing Prices, 17 TEX. INTELl. ProP. L.J. 187 (2009) (citing Commissioners' Comment to UTSA $\S 1$, in TRADE SECRETS: A STATE-BY-STATE SURVEY, supra note 80, at 3084, and stating that the purpose of the omission of "continuous" in the Act is to "extend[] protection to a plaintiff who has not yet had an opportunity ... to put a trade secret to use.").

${ }^{77}$ Cal. Civ. Code $\$ 3426.1(\mathrm{~b})$.

${ }^{78} \mathrm{Id}$. $\S 3426.1(\mathrm{~d})$. This language comes directly from the U.T.S.A. and is not unique to California.

${ }^{79}$ San Jose Const., Inc. v. S.B.C.C., Inc., 155 Cal.App.4th 1528 (2007).

${ }^{80}$ Morlife, Inc. v. Perry, 56 Cal. App. 4th 1514, 1522 (1997) (plaintiff's belief); American Paper \& Packaging

Prods., Inc. v. Kirgan, 183 Cal. App. 3d 1318, 1325 (1986) (contract).
} 
The first prong of the USTA definition is more easily understood when broken down into two separate elements: (a) information not generally known, and (b) independent economic value. Each will be discussed separately, followed by the final definitional prong of "secrecy measures," effectively creating a three-part test.

(a) Information not generally known. First, the information claimed to be a trade secret must not be generally known or readily ascertainable by business competitors or others to whom the information would have some economic value. ${ }^{81}$ A party alleging misappropriation of trade secrets must initially be able to identify the trade secrets with "reasonable particularity" prior to discovery. ${ }^{82}$ This flexible standard requires the party to identify the alleged trade secret in a fair, proper, just and rational manner under all circumstances so that the trial court can control the scope of discovery and allow both parties the opportunity to prepare their case. ${ }^{83}$ In certain cases, a court may require the party claiming trade secret protection to "separate [the instant subject matter] from matters of general knowledge in the trade or of special knowledge to those persons who are skilled in the trade." 84 A court will often require a party to draw this distinction when the nature of the alleged trade secret makes a detailed description, alone, inadequate to allow the opposing party to learn the limits of the trade secret and to develop defenses, or to allow the court to effectively control the scope of discovery. ${ }^{85}$

(b) Independent economic value. The second element of the first prong requires that the information derive value from the fact that it is a secret. The value of the information to a competitor must be substantial; it is insufficient to know that it might have been merely helpful. ${ }^{86}$ To determine what value is substantial, it is necessary to compare the alleged secret information to information generally known. ${ }^{87}$ This requirement was codified from the common law requirement that a trade secret reflect a "competitive advantage," 88 which is especially helpful to insurers and providers wishing to keep their negotiated pricing confidential so as to maintain a competitive advantage against the rest of the market participants. The focus, therefore, is on the greater value of the alleged secret information in comparison to information of general knowledge. Any unrelated value or the value of efforts expended to create the information is not conclusive evidence of substantial value, although both are relevant to the analysis. ${ }^{89}$

\section{b. Second Prong - Secrecy measures}

The second prong of the test requires the party alleging secrecy of information to show that they have made reasonable efforts to keep the information secret. To satisfy this prong, the party must show that its secrecy efforts make it difficult for a third party to acquire the

\footnotetext{
${ }^{81}$ Syngenta Crop Protection, Inc. v. Helliker, 138 Cal. App. 4th 1135, 1172 (2006); DVD Copy Control Ass'n, Inc. v. Bunner, 116 Cal. App. 4th 241, 251 (2004).

${ }^{82}$ Cal. Civ. Code $\$$ 2019.210; Neothermia Corp. v. Rubicor Medical, Inc., 345 F. Supp. 2d 1042 (N.D. Cal. 2004).

${ }^{83}$ Advanced Modular Sputtering, Inc. v. Superior Court, 132 Cal. App. 4th 826 (2005) (rehearing and review denied).

${ }^{84}$ Diodes, Inc. v. Franzen, 260 Cal. App. 2d 244, 251, 253 (1968).

${ }^{85}$ Discovery is the pre-trial phase of litigation where each party can obtain evidence from the opposing party, including by the taking of depositions and requesting the production of documents. A court must have a sufficient understanding of the parameters of a case in order to rule on what types of information one party may request from the other.

${ }^{86}$ Yield Dynamics, Inc. v. Tea Sys. Corp. 154 Cal. App. 4th 547, 567 (2007) (stating software routines only represented trivial value because they or their equivalents could be recreated).

${ }^{87}$ Pooley et al., supra note 79, $\$ 1.7(C)$ Independent Economic Value Requirement.

${ }^{88}$ Restatement (Third) of Unfair Competition $\S 39$, cmt. d, Reporter's Note (1995).

${ }^{89}$ Id. \$39, cmt. e (value of the information); Courtesy Temp. Serv. V. Camacho, 222 Cal. App. 3d 1278,1282

(1990) (development expense).
} 
information, except by improper means. ${ }^{90}$ Such efforts include, among others, imposing an obligation of confidentiality, such as a confidentiality clause in a contract, to prevent others from sharing the information. Conversely, information easily obtainable, sold on the open market, or discovered by reverse engineering cannot constitute a trade secret. ${ }^{91}$

(1) The effect of the Restatement's and the USTA's definition on the courts

Due to the rather amorphous definition provided by the USTA for trade secrets, many courts have referred back to the First Restatement to help narrow what kinds of information can receive trade secret status in other markets. Courts that have decided cases related to commercial transactions and business investments have still invoked the "continuous use" requirement to exclude ephemeral information and align the definition of trade secrets with the legislative intent of the UTSA. ${ }^{92}$ One federal district court in New York concluded that although a company had taken all the necessary measures to maintain the secrecy of its pricing information, prices fluctuate over time in any market and cannot receive trade secret protection. ${ }^{93}$ However, since New York has not adopted a version of the UTSA, but only the common law definition of trade secret from Section 757 of the Restatement of Torts, ${ }^{94}$ this case may inform, but is not binding as to interpretation of trade secret law in states that have adopted the USTA. Courts in USTA jurisdictions may nonetheless find the New York district court's ruling to be persuasive authority in future cases of first impression.

Courts may also deny trade secret designation if the information has been disclosed even to a limited set of individuals. Therefore, price disclosures to customers on an individual basis have been found to evade trade secret protection because of the theory that disclosure would not necessarily end with the individual consumer, but could continue to be disseminated by that consumer to other third parties. ${ }^{95}$ These courts reason that once the consumer has possession of allegedly confidential information, the seller's competitor can easily obtain that information from the consumer. ${ }^{96}$ This case law seems to suggest that proponents of price transparency could successfully defend against trade secret claims if so much as one line of price data was made available to an individual consumer. In particular, the fact that Aetna has made complete price information available to its members on its website may be enough to withstand a trade secret defense asserted by the insurance company. ${ }^{97}$

(2) Pricing in healthcare: unanswered by the courts

Two federal district court cases in Minnesota and Pennsylvania attempted to tackle the question of whether healthcare pricing can be protected as a trade secret. In each case, Aspen Healthcare Metrics (Aspen) and Emergency Care Research Institute (ECRI), respectively, urged the court to find that the prices hospitals pay for implantable medical devices manufactured by

\footnotetext{
${ }^{90}$ Clark v. Bunker, 453 F.2d 1006, 1009 (9th Cir 1972) (quoting Restatement of Torts $§ 757$, cmt. b (1939)).

${ }^{91}$ Cal. Civ. Code $\$ 3426.1($ a).

${ }^{92}$ Bridy, supra note 81, at 203-04.

${ }^{93}$ Id. at 204 (citing Ivy Mar Co. v. C.R. Seasons Ltd., 907 F. Supp. 547, 558 (E.D.N.Y. 1995) and quoting: "Price decisions are made on current competitive information which fluctuates over time in any industry. ... Accordingly, that information is not likely to be accorded trade secret status.").

${ }^{94}$ Trade Secrets Law in New York, CITIZEN MEDIA LAW PROJECT (last updated May 6, 2008), available at http://www.citmedialaw.org/legal-guide/new-york/trade-secrets-law-new-york.

95 Bridy, supra note 81 , at 206.

${ }^{96}$ Id. (citing Economation, Inc. v. Automated Conveyor Systems, Inc., 694 F. Supp. 553, 556-57 (S.D. Ind. 1988) (Indiana has adopted the UTSA)).

${ }^{97}$ See further discussion of Aetna's price transparency initiative in Part IV.B.
} 
Guidant Corporation do not qualify as trade secrets as a matter of law. ${ }^{98}$ In opposition, Guidant asserted trade secret protections for the "prices paid by hospitals to Guidant for its devices." 99 Each court denied motions for summary judgment, ruling that a genuine issue of material fact remained as to whether Guidant's pricing information met the above three-step analysis. ${ }^{100}$ Ultimately, both cases settled on confidential terms before trial, leaving the merits of Guidant's trade secret claims unexamined.

Consequently, the proprietary nature of pricing information in the healthcare context remains unresolved. As for the first prong of the trade secret analysis, healthcare pricing information remains unknown and arguably has substantial independent economic value such that politicians, policymakers, and economists alike have long been advocating for increased price transparency in the healthcare market. However, these cases may serve to strengthen the second prong of the trade secret test. The confidential nature of the settlement agreements may serve as further evidence of the companies' substantial measures to maintain the concealment of their prices, weighing in favor of affording them trade secret protection.

\section{(3) Acquiring price information from government agencies}

If a state, through legislation or regulation, mandates disclosure or invites voluntary disclosure of pricing information to a government agency, such as its state exchange under the ACA, the state government's ability to share that information with competitor-insurers/providers or the public at large in light of trade secret protections is unknown. In some instances, a company may disclose information to a third party while still maintaining secrecy of the information through contract, such as a gag clause. When the third party is a government agency, however, the analysis becomes more complicated.

In California, for example, intentional disclosure of proprietary pricing information by a state agency is governed by the California Public Records Act (CPRA). ${ }^{101}$ The CPRA provides that public records are open to inspection by members of the public, unless exempted by law, and must be made promptly available upon request. ${ }^{102}$ The law allows individuals to bring actions to enforce disclosure of information if they feel it has been wrongfully withheld. ${ }^{103}$ A public record includes any writing retained by any state or local agency, regardless of physical form or characteristics. ${ }^{104}$ "This definition is intended to cover every conceivable kind of record that is involved in the governmental process and will pertain to any new form of record-keeping instrument as it is developed." 105 As a result, if the state or local government has negotiated with providers for discounted rates on healthcare services, those contracts may be obtainable via

\footnotetext{
${ }^{98}$ Cardiac Pacemakers, Inc. v. Aspen II Holding Co., 413 F. Supp. 2d 1016 (D. Minn. 2006); Emergency Care Research Institute v. Guidant Corp., 2007 U.S. Dist. LEXIS 67658 (E.D. Pa. Sept. 12, 2007).

${ }^{99}$ Guidant's First Amended Ans. \& Counterclaims, II 30.

${ }^{100}$ Cardiac Pacemakers, 413 F. Supp. 2d at 1028; Emergency Care Research Institute, 2007 U.S. Dist. LEXIS 67658 , at $* 16$. Denial of a motion for summary judgment means that both parties alleged enough conflicting facts that the court could not rule on the merits of the case at the pre-trial stage.

${ }^{101}$ Gov. Code $\S \S 6250-76.48$; see also San Gabriel Tribune v. Superior Court, 143 Cal. App. 3d 762, 772 (1983). Because the CPRA was modeled after the Freedom of Information Act (FOIA), 5 U.S.C. § 552, federal case law can be relied upon to interpret and apply the CPRA.

${ }^{102}$ Gov. Code $\S 6252$ (b). Members of the public include individual persons, corporations, partnerships, limited liability companies, firms, and associations, as well as public agencies.

${ }^{103}$ Id. $\S 6258$.

${ }^{104} I d . \S 6252$ (e) (definitions).

${ }^{105}$ San Gabriel Tribune v. Superior Court, 143 Cal. App. 3d 762, 774 (1983) (citing Assembly Committee on Statewide Information Policy California Public Records Act of 1968, 1 Appendix to Journal of Assembly 7, Reg. Sess. (1970)).
} 
CPRA. Further, if California passes legislation or regulation that mandates disclosure of healthcare price information to a government entity, individuals may be able to enforce disclosure of that information which may, in turn, negate a trade secret claim by the owner of that information.

Some exemptions to CPRA do exist. While no statutory exemption directly applies to information disclosed pursuant to a state transparency initiative, three kinds of exemptions may apply to healthcare pricing information as well as to trade secrets - \$6254(q) exemptions, the "trade secret exemption," and the "catchall exemption." Each could be used by insurers and providers wishing to maintain the secrecy of their individual prices.

Section 6254(q) exempts, in part, negotiations with providers of healthcare services by special negotiators who represent the State Medi-Cal program. It also exempts portions of a provider contract with Medi-Cal containing rates of payment for three years from the date of the contract. This and all other exemptions must be narrowly construed. ${ }^{106}$ Since no such exemption exists for private insurer negotiations or contract provisions with providers, it seems unlikely that private insurance companies and providers could successfully challenge disclosure of pricing information should it be lawfully retained by the state through a transparency initiative. Furthermore, even if individuals sought to challenge disclosure of information by a government agency, CPRA would not allow them to bring actions to prevent the disclosure. However, the government may appear hypocritical if its agencies collected and disseminated data from private insurance companies, while still maintaining the secrecy of its own healthcare price information.

The trade secret exemption prevents disclosure of all trade secrets under CPRA if their disclosure "is exempt or prohibited pursuant to federal or state law including...the Evidence Code relating to privilege." 107 Although the exemption references only the Evidence Code as basis for trade secret protection, it has been interpreted to incorporate by reference all statutory and common law bases for the protection of trade secrets, including the UTSA. ${ }^{108}$ Thus, the analysis returns to the original inquiry to determine whether the information qualifies as a trade secret.

The catchall exemption protects confidential information if "the public interest served by not disclosing the record clearly outweighs the public interest served by disclosure."109 Private insurers could contend that the risk of healthcare price increases posed by price transparency is high enough that disclosure of healthcare price information does not serve the public's interest. While reputable data and analysis exist about the possible negative outcomes of price transparency, without more conclusive studies in the healthcare market this argument is unlikely to meet the onerous burden of clearly outweighing the benefit of disclosure. Further, recent case law suggests that it is becoming increasingly difficult to protect proprietary information under the catchall exemption. ${ }^{110}$

Finally, local city ordinances may provide additional regulations pertaining to disclosure of proprietary information. San Francisco's Sunshine Ordinance, established by Chapter 67 of

\footnotetext{
${ }^{106}$ Board of Trustees of California State University v. Superior Court, 132 Cal. App. 4th 889 (2005).

${ }^{107}$ Gov. Code $\S 6254(\mathrm{k})$.

${ }^{108}$ Pooley et al., supra note 79, $\$ 5.22$ Trade Secret Exemption (urging that, because the trade secret exemption was enacted prior to the passage of the UTSA, practitioners should not hesitate to argue that the limited the limited scope of the Evidence Code should not apply).

${ }^{109}$ Gov. Code $\S 6255$ (a). See State Bd. of Equalization v. Superior Court, 10 Cal. App. 4th 1177 (1992).

${ }^{110}$ See, e.g., County of Santa Clara v. Superior Court, 170 Cal. App. 4th 1301 (2009) (demonstrating that any doubt should be resolved on the side of disclosure).
} 
the San Francisco Administrative Code, is the city's version of the CPRA. ${ }^{111}$ Under the Sunshine Ordinance, the Director of Public Health may withhold proposed and final payment rates for managed care contracts for its employees. ${ }^{112}$ However, just like the CPRA, this exemption, narrowly interpreted, does not extend to private health insurance contracts with providers and hospitals.

The potential for insurers or providers to claim that the specific prices negotiated in their contracts constitute trade secrets could be a substantial barrier to price transparency initiatives. In general, the courts have left substantial uncertainty as to whether healthcare prices deserve trade secret protection. ${ }^{113}$ However, in California, the exemptions to CPRA should support an argument against offering trade secret protections to healthcare price information. ${ }^{114}$ Further, private entity negotiations under Section 6254(q), combined with a showing that, on balance, public disclosure of healthcare prices weighs in the public's interest under the catch-all exemption, seem to suggest that those entities seeking trade secret protection will have an uphill battle. $^{115}$ If California courts affirmatively denied trade secret protection to healthcare price information, such a decision could serve to clarify muddied precedents in other states as well.

4. PROVIDER RESISTANCE

In addition to legal barriers created by gag clauses and trade secrets claims, provider resistance may create a substantial barrier to improving the transparency of healthcare prices at the provider-insurer level. Even if the contractual and trade secrets issues were eliminated, provider leverage and resistance have the capacity to render price transparency initiatives ineffective and therefore should be readily addressed in any price transparency initiative.

Providers may resist price transparency initiatives mandating public reporting and antitransparency clauses in their contracts. ${ }^{16}$ For instance, Aetna's online description of its price transparency initiative cites "provider resistance as limiting the extent to which they can make price information available to their members." 117 This resistance to transparency is logical, if physicians are paid on a fee-for-service basis. ${ }^{118}$ In a fee-for-service system without transparency, physicians are financially incentivized to order increasing numbers of tests and procedures because most consumers have no way of knowing the costs or the relative benefit of the procedure. In a value-based purchasing system, which the ACA hopes to achieve, price transparency can actually help improve quality of care while lowering costs. For example, providing greater reimbursements for physicians who provide increased preventative care and follow-up visits after certain procedures can shift provider incentives away from quantity of care and toward keeping patients well and out of the doctor's office. ${ }^{119}$

\footnotetext{
111 The San Francisco Sunshine Ordinance (added by Ord. 265-93, App. 8/18/93; amended by Proposition G, 11/2/99), available at http://www.sfbos.org/index.aspx?page=5551\#67.2 (last accessed Oct. 8, 2012).

${ }^{112}$ Id. at Sec. 67.24(e)(2).

${ }^{113}$ See Cardiac Pacemakers, supra note 103 (where the lawsuit settled before the court could decide the trade secret claim), and Nunes v. The Hospital Committee for Livermore-Pleasanton Areas (Cal. Ct. App., May 29, 2012, A131060) 2012 WL 1925537 (an unreported case where, similarly, the court ruled on a motion for summary judgment before tackling the question of alleged trade secret protection).

114 See Gov. Code $\S 6254(\mathrm{q})$, (k) and $\S 6255(\mathrm{a})$.

115 Gov. Code $\$$ 6254(q); GAO REPORT ON PRICE TRANSPARENCY, supra note 67, at 9.

${ }^{116}$ GAO REPORT ON PRICE TRANSPARENCY, supra note 67, at 27.

${ }^{117}$ Id. at 22; see also Aetna's Healthcare Cost Transparency Tools, http://www.aetna.com/producer/e.briefing/200902/nat2_09_trans.html (last visited Sept. 24, 2012).

${ }^{118}$ BROWNLEE, supra note 70.

${ }^{119}$ Id
} 
Not all providers oppose price transparency. Some have spoken out in favor of it. In written comments prepared for the August 25, 2012 California Health Benefit Exchange Board Meeting, insurers, provider groups, and other healthcare advocacy groups who partner with providers expressed their support for the exchange staff's recommendation to prohibit antitransparency clauses (gag clauses) in insurer-provider contracts. ${ }^{120}$ Their support for transparency incorporated all of the above-mentioned intended effects, including cost-savings and creating well-informed consumers as a way to drive consumerism and lower prices. Although price transparency has seen some support from provider groups, in most instances, those seeking to advance a price transparency initiative should be prepared for resistance from providers.

\section{EMPLOYER-LEVEL PRICE TRANSPARENCY}

Employers represent a third target group for potential price transparency initiatives aimed at decreasing healthcare spending. At a time when employers are facing a number of long-term challenges, such as controlling costs, improving employee engagement and accountability, and determining how to comply with new healthcare reform legislation, price transparency initiatives targeting employers that either purchase health insurance or healthcare services directly from providers have great potential to reduce overall healthcare costs. ${ }^{121}$

Employers become consumers of healthcare when they contract with insurers to offer health plans to employees. If employers could obtain both quality information on the providers included in a health plan as well as the negotiated prices, they could begin to use their leverage as purchasers to demand higher value plans and avoid plans that pay inflated rates to certain providers. Knowledge of insurer-negotiated prices will also enable self-insured employers to demand lower prices and develop networks of high value providers. Employers, especially large, self-insured employers, are in a better position to accumulate and analyze price and quality data than individual consumers and they also have the ability to leverage their employees' purchasing power to negotiate price. Further, groups of like-minded employers, like the Leap Frog Group or The Pacific Business Group on Health, may have an even greater ability to leverage their position to insist on higher value plans. ${ }^{122}$ More so than individual consumers, or even insurers and providers, employers are uniquely situated to have a game-changing impact on the way price transparency can affect the healthcare system.

\footnotetext{
${ }^{120}$ Stakeholder Input: Qualified Health Plan Policies and Strategies to Improve Care, Prevention and Affordability, CALIFORNiA HEALTH BENEFIT EXCHANGE, Aug. 10, 2012, available at http://www.healthexchange.ca.gov/ BoardMeetings/Documents/August_23_2012/IX_StakeholderConsolidatedCommentsQHPPoliciesandStrategies_814-12.pdf. Those expressing support of prohibiting anti-transparency clauses in provider contracts included the California Pan-Ethnic Health Network, Castlight Health, Health Access, VSP Vision Care, Pacific Business Group on Health, Blue Shield of California. However, Blue Shield of California believes it is too soon to address contract regulation because (a) providers will resist, and (b) it is too soon before apps for QHPs are due to change any existing contracts. The lone group in opposition was the California Medical Association, due to a worry about a lack of concomitant provider protections and no way to protect providers from inaccurate and unfair reporting.

${ }^{121}$ See infra PartVI.D.

${ }^{122}$ See The Leapfrog Group, http://www.leapfroggroup.org, and The Pacific Business Group on Health, http://www.pbgh.org.
} 


\section{A. EMPLOYER-SPONSORED HEALTH INSURANCE}

Employer-sponsored health insurance is the leading source of health insurance in the United States, covering about 149 million persons under age 65. ${ }^{123}$ Employer-sponsored health insurance premiums have continued to rise in recent years, rising three and four percent for individuals and families, respectively, from 2011 to 2012 alone. ${ }^{124}$ One factor that contributes to increasing cost is continued demand for plans with broad healthcare networks for their employees. In the 1990s, managed care organizations with narrow provider networks received immense backlash due to the public perception that the narrow networks amounted to indirect healthcare rationing. ${ }^{125}$ Employers consequently began to demand broader provider networks from health plans to satisfy employee desire for greater provider options. ${ }^{126}$ This demand gave providers significant bargaining leverage to negotiate higher payments from insurers, and even greater leverage for certain "must-have" providers, ${ }^{127}$ especially hospitals, while leaving other providers, with less influence, to accept lower payments in comparison. ${ }^{128}$

Since the economic recession began in 2008 , employers have increasingly shifted a larger amount of the growing healthcare costs onto employees in the form of high deductible health plans (HDHPs). ${ }^{129}$ In both the individual and employer markets, HDHPs are the latest trend in health insurance, frequently accompanied by either a health savings account or reimbursement arrangement. ${ }^{130}$ HDHPs require consumers to pay out-of-pocket for healthcare services up to a certain threshold, e.g. $\$ 10,000$, before the health plan will begin to cover a portion of healthcare costs like a traditional PPO plan. HDHPs thus trade lower monthly premiums for higher deductibles, in an effort to reduce the moral hazard that typically accompanies insurance. ${ }^{131}$

Enrollment in HDHPs has grown rapidly over the last five years. Based on data from $2011,52.4 \%$ of persons with a private plan, directly purchased or obtained through means other

\footnotetext{
${ }^{123}$ KAISER COMM'N ON MEDICAID \& THE Uninsured, THE UninsUred: A PRIMER (Oct. 2011), available at http://www.kff.org/uninsured/upload/7451-07.pdf. 56.2\% of the non-elderly American population receives insurance coverage through an employer-sponsored plan.

${ }^{124}$ KAISER FAMILY FOUND. \& HEALTH RESEARCH \& EDUCATIONAL TRUST, EMPLOYER HEALTH BENEFITS: 2012 SUMMARY OF FINDINGS 1 (2012), available at http://ehbs.kff.org/pdf/2012/8346.pdf.

${ }^{125}$ David Mechanic, The Rise and Fall of Managed Care, 45 J. HEALTH \& SOC. BEHAV. 76 (2004).

${ }^{126} \mathrm{Id}$.

${ }^{127}$ Robert A. Berenson et al., The Growing Power of Some Providers to Win Steep Payment Increases from Insurers Suggests Policy Remedies May Be Needed, 31 HEALTH AFF. 973, 973 (2012) (defining physicians and hospitals as "must-have" providers if they are necessary to attract employers and consumers, or they provide a unique service to a certain geographic area).

${ }^{128} \mathrm{Id}$.

${ }^{129}$ A Milliman, Inc. study released February 13, 2012 found that the ACA's Medical Loss Ratio rule may make it difficult for HDHPs to compete against higher-cost low-deductible plans in a ACA Insurance Exchange. The study also concludes that the Medical Loss Ratio creates disincentives for insurance companies to continue offering HDHPs. See Mark E. Litlow et al., Impact of Medical Loss Ratio Requirements Under PPACA on High Deductible Plans / HSAs in Individual and Small Group Markets http://www.hsacoalition.org/wpcontent/uploads/2012/02/Report-ABAImpactofMedicalLossRatioRequirements.pdf. However there is increasing literature to the contrary. See Parente and Feldman, 48 Health Services Research 826 (2013), stating there is a growing sense that HDHPs will do well, particularly in the Bronze and Silver category plans.

${ }^{130}$ A health savings account (HSA) is a tax exempt account owned by an individual consumer. Funds contributed to an HSA roll over and accumulate year-to-year, and job-to-job, if not spent. A health reimbursement arrangement is an employer-funded account that reimburses employees for out-of-pocket medical expenses and premiums, where any unused dollars remain with the employer.

${ }^{131}$ Moral hazard exists when an insured individual consumes more services or engages in riskier behaviors than he or she otherwise would because he or she is shielded from the true cost of care by insurance.
} 
than employment, were enrolled in an HDHP, up from $39.2 \%$ in $2007 .^{132}$ Employers, too, have discovered HDHPs as a cost-saving solution to the rapidly rising cost of insuring employees, with $26.9 \%$ of individuals with employer-based coverage enrolled in an HDHP in 2011, up from $15.6 \%$ in 2007. ${ }^{133}$ This shift to HDHPs means that insured individuals are, arguably for the first time, incentivized to pay more attention to the price and quality of healthcare. Unfortunately, unlike the rapid growth of HDHP enrollment, the availability of price information to consumers has not grown with equal speed. ${ }^{134}$ However there is a wide literature suggesting that insured consumers, no matter how much of their healthcare bill they are required to pay upfront, simply will not use additional price information to change the way they shop for healthcare. ${ }^{135}$ As a result, recent price transparency initiatives often target consumers, but initiatives focused on other entities including employers, providers, and insurers may prove more effective.

B. BARRIERS TO EMPLOYER-LEVEL PRICE TRANSPARENCY

Each of the barriers that hinder price transparency at the individual consumer and insurerprovider levels also prohibits employers from obtaining transparency price and quality information to aid them in choosing higher quality, more cost-effective health plans for their employees.

First, legal barriers, such as gag clauses and trade secrets protections, will similarly prevent employers from demanding pricing information that will enable them to select low-cost, high-quality health plans. If employers are unable to compare health plans based on both price and quality, it will prove very difficult to convince their employees that a switch to smaller provider networks is in their best interests. Further, efforts to maintain the secrecy of contract terms also minimizes the need for providers to compete for employer-sponsored plan purchasing.

Second, questionable consumer usage may prevent employers from demanding smaller network insurance plans with lower costs and higher quality. Employers will need their employees to be engaged participants in order for them to make such a great sea change in their purchasing habits.

Third, provider resistance to price transparency prevents competition in the healthcare market, which, in turn, can prevent employers from effectively comparing the cost and quality of health plans. Lack of provider competition operates as a disincentive to reveal pricing to purchasers of healthcare.

\section{CURRENT TRANSPARENCY INITIATIVES}

Not dissuaded by the significant barriers to price transparency, state governments, private insurers, and independent private entities have initiated programs relating to price transparency and the disclosure of healthcare charges. ${ }^{136}$ This Part examines these existing initiatives to

\footnotetext{
1322011 NATIONAL HEALTH INTERVIEW SURVEY, supra note 6, at 6. These figures are based on persons under age 65 with private health insurance.

${ }^{133} \mathrm{Id}$.

${ }^{134}$ Jon B. Christianson et al., Employer-Sponsored Health Insurance: Down but Not Out, CENTER FOR STUDYING HeAlth System CHANGE (Issue Brief No. 137), Oct. 2011, at 2.

${ }^{135}$ See Carl E. Schneider and Mark A. Hall, The Patient Life: Can Consumers Direct Health Care?, AM. J. LAW MED. 2009; 35(1):7-65, concluding that mandated disclosure is unlikely to accomplish the goals of shaping how medical consumers should behave. See also Kristin Madison and Peter D. Jacobson, Consumer-Directed Health Care, 156 U. PA. L. REV. PENNUMBRA 107 (2007), http://www.pennumbra.com/debates/CDHC.pdf, debating the future of consumer-directed health care.

${ }^{136}$ Madeline Kreischer, et al., State Actions Relating to Transparency and Disclosure of Health and Hospital Charges, NAT'L CONFERENCE OF STATE LEGISLATURES, http://www.ncsl.org/issues-research/health/transparency-
} 
improve disclosure, transparency, and reporting of provider charges and fees. In recent years, California has enacted a range of programs aimed at improving access to healthcare information for consumers. This Part will first examine California's combination of efforts, and then examine the initiatives of other states, a private insurer, and independent private entities.

\section{A. CALIFORNIA LAWS AND CURRENT TRANSPARENCY INITIATIVES}

California currently has four separate transparency initiatives pertaining to healthcare cost, quality or both. Each current initiative has the potential to target all three levels of price transparency - insurers, providers, and consumers. First, this section evaluates the Payers' Bill of Rights, which requires unwaivable, mandated reporting by California hospitals of prices for certain procedures. ${ }^{137}$ Second is an assessment of California Hospital Compare, a website that gathers data via voluntary reporting of quality measures. ${ }^{138}$ Third, this section provides an overview of California legislation aimed at increasing price transparency in the healthcare market: SB 751 allows insurers to disclose price and quality information to their members, ${ }^{139} \mathrm{SB}$ 1196 allows healthcare claims data to be disclosed to qualified entities. ${ }^{140}$

\section{PAYERS' BILL OF RIGHTS}

Sections 1339.50-56 of the California Health \& Safety Code, also known as the Payers' Bill of Rights, seeks to prevent hospitals from "gouging patients" and to help inform patients of the cost of healthcare procedures. ${ }^{141}$ It requires each hospital to disclose their average billed charges for the twenty-five most common inpatient and outpatient procedures to the Office of Statewide Health Planning and Development (OSHPD). ${ }^{142}$ OSHPD then publishes these charges to its website, while hospitals must make the list of procedures and charges available to any person upon request. ${ }^{143}$ Any person who believes a hospital is in violation of the Payers' Bill of Rights may file a claim with the California Department of Public Health (CDPH), which investigates such claims to determine whether a violation has occurred. ${ }^{144}$

The Payers' Bill of Rights also requires hospitals to make its chargemaster, a list of the hospital's gross billed charges, for the specific services or items publicly available. ${ }^{145}$ Chargemaster prices are important because they are prices billed regardless of a patient's insurance coverage and are the starting point for discounted prices by insurers. ${ }^{146}$ While a step in the direction of price transparency, the chargemaster amounts can represent more than double the

and-disclosure-health-costs.aspx (last visited February 11, 2013) (summarizing signed laws and proposed state legislation).

${ }^{137}$ Cal. Health \& Safety Code $\S 1339.52$ (waivers prohibited).

${ }^{138}$ CALHOSPITALCOMPARE.ORG, http://www.calhospitalcompare.org/about-us.aspx (last visited Oct. 22, 2012).

${ }^{139}$ Cal. Health \& Safety Code $\S 1367.49$.

${ }^{140}$ Id. $\S 1367.50$.

${ }^{141}$ CRS REPORT FOR CONGRESS, supra note 9, at 27.

${ }^{142}$ Cal. Health \& Safety Code $\$ 1339.56$ (list of charges for common services and procedures).

${ }^{143} \mathrm{Id}$. OSHDP publishes both the average and median charges for each service and item.

${ }^{144}$ Cal. Health \& Safety Code $\S 1339.54$ (claims of violations; investigation); see also Healthcare Information Division: Annual Financial Data General Information About the Hospital Chargemaster Program, OFFICE OF STATEWIDE HEALTH PlanNing \& DEV'T (last updated Aug. 8, 2012), http://www.oshpd.ca.gov/HID/Products/ Hospitals/Chrgmstr/index.html ("This process would also pertain to any person who has no healthcare coverage and requested a written estimate from a hospital for healthcare services, procedures and supplies or requested information and/or an application for financial assistance or charity care and received no response from the hospital.”).

${ }^{145}$ Cal. Health \& Safety Code $§ 1339.51$ (charge description master; posting; notice).

${ }^{146}$ CRS REPORT FOR CONGRESS, supra note 9, at 19. 
actual prices insurance companies pay for the listed services and, therefore, bear little relationship to the actual cost of the healthcare services provided to the insured consumer. ${ }^{147}$

So far, the Payers' Bill of Rights has had little to no observable effect on hospital pricing. Several factors contribute to its ineffectiveness. First, each hospital is allowed to determine which twenty-five outpatient procedures to report to OSHPD, making comparisons between hospitals' list of charges not always possible. ${ }^{148}$ Second, because insured patients do not pay the prices listed, these prices are not likely to be helpful to the average insured consumer who is insulated from gross charges via their health insurance plan. ${ }^{149}$ For example, if the average price for a hospital stay varies significantly between two hospitals, but the out-of-pocket costs to a consumer are the same, access to the average price information on a chargemaster is unlikely to influence a consumer's decision in favor of a lower cost provider and may even signal the higher priced provider as offering higher quality services. Consumers in high deductible health plans (HDHPs) or with a plan that requires coinsurance payments will, however, benefit from knowing what their provider is charging their insurer, because that, in turn, will determine their out-ofpocket costs. Knowledge of these price figures could allow these consumers to determine whether their insurer is paying more for a particular service from one provider to another, thus giving consumers the capability to provider-shop within their network before even making an appointment. Further, the chargemaster prices are not specific to particular health plans, which may be of no help at all to insured consumers who are only concerned with the price of a service as it relates to their plan. Since the total number of insured individuals is expected to rise dramatically in 2014 when coverage on the health benefit exchanges takes effect, it will become increasingly important for price transparency initiatives to convey price information based on health plan.

Third, OSHPD's website does not provide an adequate explanation of chargemaster prices to allow the average consumer to decipher the meanings of the listed gross figures. Instead, the website includes vague disclaimers stating that charges will vary significantly from one patient to the next. These disclaimers tend to negate the transparency initiative altogether since the website has no mechanism for disclosing more consumer-specific prices. The website simultaneously highlights the industry's complex billing practices by disclaiming the discrepancies between each patient's cost of care. More successful price transparency initiatives provide supplemental information for consumers to consider along with price when making decisions about a hospital. ${ }^{150}$ Aetna's website, for example, provides a more helpful disclaimer to educate consumers that high quality and low price are not mutually exclusive measures. ${ }^{151}$

Lastly, comparable quality data is completely absent from the information presented via the chargemaster. The inclusion of quality data would give the listed prices the necessary context to be meaningful information for consumers. ${ }^{152}$ The website does provide volume data, which could be helpful if paired with quality and price data, allowing consumers to choose

\footnotetext{
${ }^{147}$ Reinhardt, supra note 15, at 57-58 (citing American Hospital Association, Hospital Statistics (2005)).

${ }^{148}$ Healthcare Information Division: Annual Financial Data General Information About the Hospital Chargemaster Program, OfFICE OF STATEWIDE HeALTH PlanNING \& DEV’T, http://www.oshpd.ca.gov/HID/Products/ Hospitals/Chrgmstr/.

${ }^{149}$ CRS REPORT FOR CONGRESS, supra note 9, at 30.

${ }^{150}$ GAO REPORT ON PRICE TRANSPARENCY, supra note 67, at 22

${ }^{151} I d$. at 24. Further examples are provided in Part V.D.2.

${ }^{152}$ Id. at 22; Hibbard \& Peters, supra note 38, at 415 (2003).
} 
physicians based on the number of times they have performed a procedure. However, this data alone is not as useful, and is unlikely to have much effect on consumer choice. ${ }^{153}$

\section{CALIFORNIA HOSPITAL COMPARE}

A second transparency initiative is California Hospital Compare, a website launched by the California Healthcare Foundation, in partnership with the University of California, San Francisco, and the California Hospitals Assessment and Reporting Taskforce (CHART) to compare hospital quality information. ${ }^{154}$ This website includes ratings for clinical care, patient safety, and patient experience for over 230 hospitals that voluntarily self-report quality measures related to the most common procedures. Conversely to OSHPD's website, the quality data presented on CalHospitalCompare.org are not linked to price data. The website provides a link where individuals can go to the OSHPD site to see average pricing data, but without a connection drawn between the two, consumers are likely to find it too challenging to successfully integrate the available cost and quality information for effective use in healthcare decision-making. ${ }^{155}$

3. ENACted AND PROPOSED LEGISLATion to AVOID CONTRACTUAL BARRIERS to TRANSPARENCY

In addition to requiring providers to make price and quality information available, the California Legislature recently addressed the problem of gag clauses in provider-insurer contracts by passing two laws that promote healthcare price transparency-Senate Bills (SB) 751 and 1196. Both laws amend section 1367 of the California Health and Safety Code to prohibit contract provisions that would restrict the transparency of healthcare data, also known as "gag clauses." SB 751, effective January 1, 2012, targets transparency at the consumer level by allowing price and quality information to be made available to enrollees of health plans. ${ }^{156} \mathrm{SB}$ 1196, effective since January 1, 2013, pertains to the disclosure of claims data to qualified entities. $^{157}$

SB 751 renders void and unenforceable any contract between an insurer and a licensed hospital or healthcare facility that contains a gag clause. ${ }^{158}$

A contract issued, amended, renewed, or delivered on or after January 1, 2012, by or on behalf of a healthcare service plan and a licensed hospital or any other licensed health care facility owned by a licensed hospital to provide inpatient hospital services or ambulatory care services to subscribers and enrollees of the plan shall not contain any provision that restricts the ability of the health care service plan to furnish information to subscribers or enrollees

\footnotetext{
${ }^{153}$ Hibbard \& Peters, supra note 38, at 415-16 (stating that pieces of information that do not inherently relate to each other, such as trade-offs, create burdensome cognitive processing that will result in consumers choosing to allow one factor to drive their entire decision making process in order to ease the burden).

${ }^{154}$ CALHOSPITALCOMPARE.ORG, http://www.calhospitalcompare.org/about-us.aspx (last visited Oct. 22, 2012).

155 There is also a way to search for free and discount payment programs for hospital services. See California Hospital Free and Discount Payment Programs, OfFice OF Statewide Health Planning \& DeV’T, http://syfphr.oshpd.ca.gov/search.aspx (last visited Oct. 21, 2012).

${ }^{156}$ Cal. Health \& Safety Code $\$ 1367.49$, Section 1 of Stats. 2011, c. 244 (S.B.751) ("It is the intent of the Legislature to ensure that subscribers and enrollees of a health care service plan, and policyholders and insureds of a health insurer, can make informed decisions about their health care choices.").

${ }^{157}$ SB-1196: Claims Data Disclosure, CALIFORNIA LEGISLATIVE INFORMATION (2012), available at http://leginfo.legislature.ca.gov/faces/billNavClient.xhtml?bill_id=201120120SB1196 (last visited Oct. 2, 2012).

${ }^{158}$ Cal. Health \& Safety Code $\$ 1367.49$ (a)-(b) (ability of healthcare service plan to furnish information to subscribers or enrollees concerning cost range of procedures or quality of services at hospital or facility; contractual provisions; statement posted on Internet website).
} 
of the plan concerning the cost range of procedures at the hospital or facility

or the quality of services performed by the hospital or facility. ${ }^{159}$

The law does not require insurers to disclose this information; it merely removes any contractual barriers that may prevent insurers from doing so. ${ }^{160}$ For example, when previously hospitals would demand confidentiality clauses in insurer contracts, preventing health plans from disclosing prices paid to those providers to their members, hospitals can no longer prevent those health plans from choosing to make provider price information available to consumers on their plans. Although not explicitly stated in the statutory language, SB 751 does not prevent an insurer from using its discretion to refuse to disclose cost range and quality information to subscribers. Thus, the law does not mandate price transparency, but merely removes a contractual barrier to achieving it, should insurers choose to do so.

Two significant limitations of SB 751 are as follows: (1) The law allows only a cost range to be disclosed, and (2) the timing of the intervention by disclosing cost and quality information only to subscribers or enrollees of a health plan limits the potential effects of transparency.

First, by prohibiting contractual barriers to disclosure of the range of costs to consumers, the legislature has created a similar problem to the Payers' Bill of Rights-that a potentially large range of prices for one procedure may provide little, if any, guidance to consumers attempting to select a hospital. Whether this information will help consumers make more informed decisions will depend on how narrow the cost ranges are. Disclosure of a larger range of prices for each facility will restrict consumers' ability to make comparisons, whereas a smaller range of prices may allow for better comparison of facilities. Further, this bill received substantial opposition from the University of California (UC), the state's fourth largest healthcare delivery system, in its letter to the Assembly Health Committee Chair opposing SB 751. In its letter, UC stated that the bill's lack of built-in "means or assurances that consumers will receive meaningful and relevant information on provider cost and quality" prevents consumers from receiving the most valuable and accurate information in order to make informed healthcare choices. ${ }^{161}$ While SB 751 requires insurers to include several risk adjustment factors along with any quality measures they choose to disclose to their members, SB 751 mandates no such risk adjustment factors in conjunction with price information to ensure maximum consumer usability of quality information. Without certain risk adjustment factors, such as severity of condition and type of facility (i.e. community hospital or academic medical center), consumers may be unable to draw meaningful comparisons across hospitals and providers. ${ }^{162}$

The second limitation of SB 751 stems from the elimination of gag clauses as they relate to the disclosure of information to health plan "subscribers and enrollees" only, instead of to consumers prior to choosing a health plan. ${ }^{163}$ By only preventing anti-transparency clauses from precluding disclosure to enrollees and subscribers, SB 751 limits the potential for transparency to lower healthcare costs. SB 751 does not bar contracts from preventing disclosure of price and quality measures to non-enrollees; insurers and providers may still keep this information secret

\footnotetext{
${ }^{159} I d . \S 1367.49$ (a).

${ }^{160}$ The law also states that the hospital or facility must be allowed "at least 20 days to review the methodology and data compiled by the health care service plan," as well as "an opportunity to provide an Internet Web site link" with a timely written response to the reported cost and quality information.

${ }^{161}$ Letter to The Honorable William Monning, Chair, Assembly Health Committee, on behalf of the University of California (June 8, 2011).

${ }^{162} \mathrm{Id}$.

${ }^{163}$ Cal. Health \& Safety Code $\S 1367.49$ (a).
} 
from uninsured consumers, preventing consumers from comparing hospital price ranges on different health plans prior to enrollment. If the law required disclosure of price and quality information to consumers prior to enrollment, both providers and insurers could be forced to compete for business at an earlier stage, thus potentially driving down prices not just for one insurer, but across multiple carriers. Still, these effects depend on whether the healthcare market reacts to price transparency like a traditional economic market.

One positive effect of SB 751 is that it may provide a defense to a trade secrets claim by providers and insurers who wish to challenge any mandated disclosure of price information. The interplay between the California UTSA and SB 751 has not yet been addressed by the courts. The question remains as to whether cost range information furnished to subscribers of a health plan under SB 751would make actual prices that insurers pay to healthcare facilities matters of general knowledge, or whether cost range information is so different from the actual facilities' prices that those prices can still be considered "special knowledge" under the California UTSA. Providers could argue that disclosure of cost range information is so broad (i.e. does not reveal the actual prices of procedures) that actual price information remains secretive and should receive trade secret status. However, the possibility that actual price information could be obtained from the disclosed cost ranges by reverse engineering could cause a trade secret claim to fail.

SB 1196 appears to take SB 751 one step further. Although the law pertains solely to price information, it expands the disclosure of healthcare prices beyond just enrollees of health plans to the public. The law prohibits contracts between a health plan and a provider, including a provider of supplies, from containing any provision that prohibits, conditions, or in any way restricts the disclosure of claims data related to healthcare services provided to enrollees, insureds, or beneficiaries of any self-funded health coverage arrangement to "qualified entities" as determined by the Centers for Medicare and Medicaid Services (CMS). 164 The Secretary of CMS recognizes qualified entities to make evaluations of provider/supplier performance and to agree to meet specific requirements regarding the transparency of their methods and their use and protection of data.

To be certified as a qualified entity, an organization- "either a single public or private entity, or a lead entity and its contractors"-must submit to CMS an application package that includes information demonstrating that the applicant will satisfy the requirements specified in 42 CFR $\S 401 G$ (401.700-.721), as well as other criteria determined by CMS. ${ }^{165}$ Among other requirements, applicants must demonstrate existing expertise and sustained experience (defined as three or more years) in performance measurement, the ability to combine Medicare data with existing claims data, a process for allowing providers to review and correct their performance reports, and adherence to rigorous data privacy and security procedures. ${ }^{166}$ If it demonstrated sufficient expertise, an exchange could apply to be a qualified entity; alternatively, a group of healthcare stakeholders organized as a single entity, as required by section 401.703(a), could perform the same function. Once determined to be qualified, a multi-stakeholder organization that represented a range of interests in healthcare could collect price data and determine the best

\footnotetext{
${ }^{164}$ Cal. Health \& Safety Code $§ 1367.50$ (defining a "qualified entity," pursuant to 42 USC 1395kk, as a public or private entity "that is qualified (as determined by the Secretary) to use claims data to evaluate the performance of providers of services and suppliers on measures of quality, efficiency, effectiveness, and resource use"). ${ }_{165} I d$.

${ }^{166} 42$ CFR § 401.700-.721; Qualified Entity Certification Program for Medicare Data, https://www.qemedicaredata.org/SitePages/about.aspx (last visited Nov. 4, 2012) (stating that applications will be accepted on a rolling basis).
} 
way-in the interest of all stakeholders - to use that information. Such an organization could potentially partner with California's Health Exchange, Covered California, to inform its decisions.

\section{B. OTHER STATE INITIATIVES}

In other states, some current transparency initiatives provide access to complete cost information, while others use only limited price data. Complete cost information is the disclosure of a price that incorporates all discounts, includes associated costs such as lab fees, and identifies out-of-pocket costs. ${ }^{167}$ Complete cost information allows patients to anticipate all potential costs they could be responsible for when undergoing a particular procedure. On the other hand, limited price data or price averages enhance the risk that consumers will feel misled by the information or not use the information at all. ${ }^{168}$

While complete cost information can be extremely difficult to obtain due to confidential agreements between insurers and providers, two price transparency initiatives - one public and one private - demonstrate that providing complete cost information is potentially attainable. However, whether transparency will affect consumer decision-making or provider-insurer negotiations will depend on successful implementation.

The first example is the public initiative of the state of New Hampshire: HealthCost. Since 2007, HealthCost has disseminated complete medical cost information by insurance plan and procedure, as well as prices for uninsured consumers. ${ }^{169}$ Directed at individual consumers and employers, the website lists specific prices that reflect negotiated discounts and other reductions from the billed charges obtained through claims data. ${ }^{170}$ Insured users enter their insurance plan, their deductible amount, and their percentage rate of co-insurance, and the website uses that data to calculate their out-of-pocket costs as well as the total cost of the service by provider. The website is updated quarterly to reflect the most recent changes in pricing. However, New Hampshire does not provide quality data as a part of its price transparency initiative. This leaves consumers unable to truly compare providers and leaves open the question of whether higher prices reflect higher quality care.

Other states have not gone as far in their price transparency initiatives. The Massachusetts initiative, MyHealthCareOptions, provides a median and range of insurers' aggregated payments made to particular provider groups and hospitals based on claims data. ${ }^{171}$ While Massachusetts, like New Hampshire, has access to claims data that could be used to provide complete cost transparency to its consumers, it instead provides average prices paid by private insurers for specific services. This is due, in part, to insurers' and providers' concerns about the initiative disclosing insurer-specific information to consumers, as well as a lack of technical capabilities to identify which hospital and physician data should be linked. ${ }^{172}$ Consumers, therefore, cannot see a price estimate that is specific to their insurer, much less their specific health insurance plan or their specific treatment.

\footnotetext{
${ }^{167}$ GAO REPORT ON PRICE TRANSPARENCY, supra note 67, at 24.

168 Sinaiko \& Rosenthal, supra note 16 , at 892.

${ }^{169}$ NH HEALTH COST, http://nhhealthcost.org (last visited Oct. 22, 2012).

${ }^{170}$ GAO REPORT ON PRICE TRANSPARENCY, supra note 67, at 24.

${ }^{171}$ MyHealthCareOptions, MASS.GOV, http://hcqcc.hcf.state.ma.us/Content/AboutTheRatings.aspx\# (last visited Aug. 28, 2013).

172 GAO REPORT ON PRICE TRANSPARENCY, supra note 67, at 27 (explaining that since not all insurance plans are consistent in how they report physician fees, the initiative cannot use the available claims data).
} 


\section{PRIVATE INSURER}

Similar to New Hampshire's HealthCost, Aetna's “Member Payment Estimator" provides complete cost information to members through access to the insurer's negotiated discounts with providers. ${ }^{173}$ Prices for each service are provided as "service bundles." This means that when a member searches for the price of a cesarean section, the generated price includes the costs likely to go along with that procedure, e.g. anesthesia and blood work, giving members a more complete picture of the cost. ${ }^{174}$ For calculating estimated out-of-pocket costs, Aetna links member data to its price transparency website, which then automatically updates and calculates the member's estimated costs in real-time. ${ }^{175}$ Aetna's transparency initiative also provides consumer education that high price does not always mean high quality, and informs consumers that low cost/high quality healthcare does exist. ${ }^{176}$ However Aetna's member-only access to complete cost information precludes employers and individual consumers from accessing the Member Payment Estimator until they have already committed to the health plan. Further, member-only access still prevents other insurers and providers from accessing these figures, which does not facilitate competition among health plans.

\section{INDEPENDENT PRIVATE INITIATIVES}

Finally, there exist three private, web-based initiatives that are not affiliated with a specific insurance plan. The first of these is Clear Health Costs, a company that gathers data from independent reporting, including from health-care providers, participating consumers, and other databases, to bring transparency to consumers in the healthcare market. ${ }^{177}$ The goal of this website is to "empower[] consumers to make informed decisions about costs of their medical care and coverage." 178 The website currently focuses on common procedures and items in the New York City and San Francisco areas, and provides Medicare pricing information for these procedures in all other states. ${ }^{179}$ Within the two focus areas, the website provides the highest and lowest cash prices for uninsured consumers per procedure charged by specific providers, in addition to varying price reports from the company's various reporting sources. ${ }^{180}$

Another private transparency initiative has been launched by Compass Professional Health Services ("Compass"). Compass provides healthcare pricing information to employers and individual consumers who pay an annual membership fee. ${ }^{181}$ In addition to consumer advocacy and helping consumers and employers to find low-cost, high-quality healthcare, Compass's website also contains a blog and news reports on the latest changes in the healthcare industry, as well as several white papers directed at helping consumers select the best health

\footnotetext{
173 Member Payment Estimator, AETNA, http://www.aetna.com/individuals-families-health-insurance/tool/memberpayment-estimator.html (last visited Feb. 19, 2013).

${ }^{174} I d$.

${ }^{175} \mathrm{Id}$.

${ }^{176}$ GAO REPORT ON PRICE TRANSPARENCY, supra note 67, at 24.

177 The Pros and Cons of Health-Cost Transparency, CleAR HeAlth Costs (Mar. 14, 2011), http://clearhealthcosts.com/blog/2011/03/the-pros-and-cons-of-health-cost-transparency.

${ }^{178}$ About, CLEAR HEALTH COSTS, http://clearhealthcosts.com/about (last visited Oct. 22, 2012).

${ }^{179} \mathrm{Id}$. The website states the initiative is focused on the New York City area, but recent email exchanges with a company representative revealed that specific pricing information is now available also for the San Francisco area and that the company is planning to expand.

${ }^{180} \mathrm{Id}$. Each price is disclosed alongside the provider's full name and address.

${ }^{181}$ COMPASS PROFESSIONAL HEALTH SERVICES, https://www.compassphs.com/index (last visited Oct. 22, 2012).
} 
plans and save money. ${ }^{182}$ For uninsured consumers who are trying to save money on healthcare costs, Compass does not seem to be the best cost-saving solution. However for employers, a few hundred dollars per year in membership fees may be worth the $25 \%$ savings proposed by Compass's services. ${ }^{183}$

A third private transparency initiative is Castlight Health. Since 2008, this San Francisco company has been offering an online portal that allows self-insured employers to provide quality assessment and price transparency information to employees. ${ }^{184}$ Castlight Health also has partnered with health plans to help deliver cost and quality information directly to plan members, including individuals and small businesses, with the belief that enabling consumers to make better-informed decisions when purchasing healthcare will drive quality up and costs down. While there are no consolidated results of Castlight's efforts on their website, the multitude of positive testimonials suggests that Castlight has successfully enabled employers, employees and individual consumers to realize significant savings. ${ }^{185}$

\section{EXISTING INITIATIVE EFFECTIVENESS}

Each of the state and private initiatives targeting individual consumers discussed above provide helpful information to consumers, but none provides all the necessary components for what potentially could be the most effective consumer-targeted transparency. For price transparency to be most effective, complete cost information must give customers an accurate and actionable picture of their healthcare costs. ${ }^{186}$ While the Massachusetts Connector is unable to provide complete costs, both the Aetna and New Hampshire initiatives have demonstrated that this level of disclosure is possible. Bare pricing information, however, like that of New Hampshire's initiative, without providing more explanation and context, may have the effect of misleading consumers into believing that higher price is always indicative of better quality care. ${ }^{187}$ Ideally, transparency of healthcare prices alongside quality measures would meaningfully assist consumers, and those making decisions on their behalf (employers, health carriers, and referring practitioners) in making more informed healthcare decisions. ${ }^{188}$ Judith Hibbard, a health policy professor and researcher, argues that consumers will not use information they do not understand because of unwillingness to go through the process of trying to make sense of the information and match it up with other factors, such as quality, provider or peer recommendations, and location. ${ }^{189}$ The most effective transparency initiative, Hibbard asserts, will reduce the mass of information into an index that consumers can easily understand. Only then can consumer choice have a large enough impact on the healthcare market to actually lower costs.

Theoretically, a more informed consumer population choosing higher-quality and lowercost healthcare services could force providers and hospitals to not only charge competitive prices

\footnotetext{
${ }^{182}$ Keys to Success, COMPASS PROFESSIONAL HeALTH SERVICES, https://www.compassphs.com/about-compasswhite-papers (last visited Oct. 22, 2012). The most recent white papers are entitled, "7 Key Strategies for Effective Cost Containment" and "8 Mistakes To Avoid When Selecting a Health Plan."

${ }^{183}$ COMPASS CASE STUDY (2012), available at https://www.compassphs.com/files/casestudies/Compass_Case_ Study.pdf. A 6,000 employee company saved $\$ 4.5$ million dollars in a year by moving to a consumer-directed health plan and enlisting Compass's services.

${ }^{184}$ CASTLIGHT HEALTH, http://www.castlighthealth.com (last visited Oct. 22, 2012).

${ }^{185} \mathrm{Id}$.

${ }^{186}$ GAO REPORT ON PRICE TRANSPARENCY, supra note 67, at 28.

${ }^{187}$ Id. at 23.

${ }^{188}$ Ginsburg, supra note 73, at 209.

${ }^{189}$ Id. (citing Hibbard \& Peters, supra note 38).
} 
for healthcare services, but could also provide an incentive to increase quality of care. Aetna's website is an example of this contextual transparency with cost and quality available in concert. However, Aetna's transparency falls short of its full potential by limiting disclosure of that information to its members only. Further, all of these initiatives target the consumer-level only. At a time when employees and employers have so much more at stake than before, employereducation initiatives like Castlight will also be an integral part of ensuring effective price transparency.

While state government and private insurers have yet to launch a price transparency initiative that is proven to lower healthcare costs, each of the three independent private organizations have sought to fill the regulatory gap and offer employers and individual healthcare consumers valuable information to help them lower their healthcare costs.

\section{POTENTIAL SOLUTIONS TO PROMOTE EFFECTIVE PRICE TRANSPARENCY}

As demonstrated above, price transparency initiatives can be implemented through a variety of methods. This Part examines a range of potential legal and educational initiatives designed to promote price transparency. The legal solutions include antitrust litigation, legislative solutions, and exchange regulations. Next, this Part will explore possible educational initiatives for employers and consumers to promote price transparency. Part VIII will then offer recommendations for combinations of potential solutions.

\section{A. LeGiSLATIVE SOLUTIONS}

One possible solution is for states to continue to try to promote price transparency through legislation. Price transparency legislation will have varied effects, depending upon particular conditions in the target market. In urban areas with a higher concentration of providers, less leverage, and greater market competition, price transparency may drive price decreases, while rural areas with fewer providers may actually see healthcare prices increase. The potential for geographically varied outcomes results from provider leverage over certain markets, where more leverage exists for "must-have" providers and providers supplying unique services within a network. ${ }^{190}$ As a result, blanket price transparency requirements should not be implemented through legislation. Instead, the legislature should focus on incentivizing price transparency in areas with less leverage and greater competition where its intended effects are most probable. With this in mind, there are three potential avenues for legislating price transparency.

First, a state legislature could pass legislation that gives the state the authority to certify individual health plans that provide the best value, both within and outside of the exchanges, as "Visible Value" plans. Exchanges could require Visible Value plans to meet specified criteria for lower cost and high quality services. Receiving certification would also signal to consumers that the plan did not result from any anticompetitive tactics such as MFN clauses or geographic tying leverage, and that it has value-based financial incentives for provider payment, rather than fee-for-service. Since complete transparency may not be an ideal solution for all markets, the law should require that insurers only disclose complete price information negotiated with providers to the exchange or other state agency in charge of certification in order to determine certification eligibility. By not releasing full price information to competitors, this will prevent collusion in less competitive markets while still allowing the state to direct consumers to those

\footnotetext{
${ }^{190}$ Berenson et al., supra note 24.
} 
health plans that offer the best quality care for the most competitive price, in the absence of anticompetitive negotiations.

In terms of transparency to the public, only certified Visible Value plans would be required to make provider quality scores and premium rates available to the public. Each certified health plan would be required to maintain quality and cost scores at a minimum level, or else lose its certification status. In addition to facilitating consumers' healthcare decisionmaking, this legislative transparency initiative may also incentivize providers to deliver higher quality care and insurers to negotiate for lower priced, better quality providers, thereby helping to lower the cost of healthcare statewide.

One challenge of this approach would be gathering and analyzing the cost and quality data needed to certify the health plans. In California, the cost portion of this data could be collected by a qualified entity, designated by CMS to gather and disseminate data on provider performance pursuant to SB 1196, ${ }^{191}$ and evaluated in accordance with the legislative criteria to determine which plans are eligible for certification. ${ }^{192}$ A state could apply to CMS for designation as a qualified entity for purposes of gathering price and quality data. Other entities, such as a multi-stakeholder group, could also apply for qualified entity status to enable collection of this information for Visible Value plans. The quality evaluation, however, would either require voluntary reporting by health plans, or would need to be collected from a quality comparison website, such as California Hospital Compare ${ }^{193}$ or "Health In Sight," a national hospital rankings website. ${ }^{194}$

This process of certifying best-value health plans would differ from the tiered health plans in that tiering is fundamentally based on cost, whereas this certification will be based additionally on quality and competitive activity. Because the success of health plan certification depends on consumer engagement and purchasing of those certified plans, education programs for individual consumers and employers will be absolutely necessary. Similar to the types of consumer education found on Aetna's website regarding provider cost and quality, ${ }^{195}$ succinct and usable information must be provided to consumers and employers to ensure full understanding of the certification process. ${ }^{196}$

States could also pass legislation requiring an annual review of all insurance premium increases of 5\% or greater. Currently, the Affordable Care Act mandates an annual review of premium rate increases of $10 \%$ or more. ${ }^{197}$ By mandating an even more strict review, states

\footnotetext{
${ }^{191}$ See Section V.A.3, supra (stating SB 1196, recently signed into law in September 2012, prohibits health planprovider contracts from preventing disclosure of claims data to "qualified entities" designated by the Secretary of the Centers for Medicare and Medicaid Services).

${ }^{192}$ As part of the ACA, Congress created a new program to make certain healthcare data available to certified "qualified entities." In 2011, CMS launched its Medicare Data Sharing for Performance Measurement program that allows qualified entities to use Medicare claims data, along with publically available data from private insurers, to produce comprehensive reports on provider performance. Using the same certification process, states, like California, could allow qualified entities to access healthcare pricing information for public dissemination.

${ }^{193}$ See Section V.A.2, supra.

${ }^{194}$ Health In Sight, Hospital Performance Rankings, available at http://www.healthinsight.org/Internal/Hospital PerformanceRankings.html.

195 See Section V.C, supra.

${ }^{196}$ See http://www.calhospitalcompare.org/resources-and-tools/why-quality-matters/how-we-rate-quality-on-thiswebsite.aspx, explaining that CalHospitalCompare.org rates hospitals on quality measures that affect health care, such as appropriate timing of antibiotics, hospital-acquired pressure ulcers, aspirin given at arrival to cardiac patients, bilateral cardiac catheterization, breastfeeding rate, and arrangements for transition to home.

${ }^{197}$ Patient Protection and Affordable Care Act, Pub. L. No. 111-148, § 1003, 124 Stat. 119 (2010).
} 
could monitor rising costs more closely. States could deny and assess penalties on insurance companies that are unable to justify their rate increase by demonstrating quality improvements or increased benefits. If triggered, annual review of premium increases of 5\% or greater could also nullify gag clauses, as insurers would be required by law to disclose information negotiated in provider contracts in order to justify their desired increase. Penalties and mandatory disclosures would provide strong additional incentives for insurance plans to keep premium increases below $5 \%$. These mandatory disclosures for auditing purposes would not be disseminated to the public; however, the information may be requested under a state's public records law, such as the CPRA, to facilitate public disclosure.

\section{B. REGULATORY SOLUTIONS}

Unlike legislation, which is created by an internal proposal from within a legislative body, voted on by both the houses and then signed by the governor, regulation can be created by any state agency with the power to enforce certain laws. While the most opportune regulations could come from the exchanges, initiatives can also be implemented outside of the exchanges by state departments of insurance.

Recent healthcare reform efforts create new opportunities to address the gap in consumer information through the state health benefit exchanges. The ACA requires states to pass legislation to legally set up an exchange, or else the federal government will administer one for them. ${ }^{198}$ The federal law gives states flexibility to set up exchanges in ways that will most benefit each state, within certain federal guidelines. The creation of state exchanges offers two opportunities for states to incorporate price transparency initiatives into these new entities: 1) legislation establishing the exchanges; or 2) regulations created by an exchange to govern qualified health plans offered on the Exchange. As the first state-created exchange, this section will use California as a model for analyzing price transparency initiatives at the exchange level.

\section{LEGISLATION GOVERNING THE EXCHANGE}

In January 2011, California became the first state to create a health benefit exchange with the passage of Senate Bill (SB) 900 and Assembly Bill (AB) 1602. SB 900 established the Exchange and created a five-member Board of Directors. AB 1602, the California ACA, creates the structural framework of the California Health Benefit Exchange, known as Covered California. The statute grants the Board the authority to determine both the minimum requirements for carriers to offer a plan on Covered California, as well as the standards and criteria required for designating a plan as a Qualified Health Plan (QHP) eligible to be offered through Covered California. Most notably, section 2(a) calls for the creation of a "transparent marketplace for Californians to purchase affordable, quality healthcare coverage." Incorporating transparency language into the legislation establishing Covered California opens the door to discussion about ways to implement a price transparency initiative in California, with hopes to pave the way for other states to follow suit.

\section{AVENUES TO EXCHANGE REGULATION AND THEIR UNCERTAINTIES}

Since California enacted legislation designating Covered California as an active purchaser, it had the authority to impose requirements, such as price transparency, on health plans that wish to be a part of the exchange. As one of its first steps to actively negotiate with health plans, the Board drafted a list of requirements and questions for plans submitting bids to be on the exchange. ${ }^{199}$ Covered California asked bidders to describe their current costs, quality,

\footnotetext{
198 Id.

${ }^{199}$ California Health Benefit Exchange, Qualified Health Plans Solicitation Draft (Sept. 25, 2012), available at http://www.healthexchange.ca.gov/Solicitations/Documents/QHP\%20Solicitation\%20DRAFTv\%20092512public.pdf.
} 
and efficiency programs, including "activities to identify for members/consumers those providers ... that are more efficient and/or lower cost" and "the web-based cost information that the Plan makes available." 200 Each bidding health plan must also reveal current cost containment strategies, describe methodology used to combine provider cost and quality metrics, ${ }^{201}$ and list any contractual agreements with its participating providers that prevent it from making contract terms transparent to plan members. ${ }^{202}$ Based on bidders' responses, the Board has the authority to fine-tune its requirements and impose even greater restrictions on insurers. ${ }^{203}$

The Board does not currently impose any price transparency requirement on health plans that wish to participate in Covered California. However, increased pressure through stakeholder testimony and written comments at meetings and in webinars may motivate the Board to mandate price transparency on the exchange. The Board strongly believes that its efforts should be guided by input from stakeholder groups. ${ }^{204}$ As a result, it invites public testimony and submission of written comments at its meetings, allows stakeholders to give panel presentations on particular issues, and holds separate webinars to assess stakeholder values and concerns. This willingness to listen to and incorporate stakeholder feedback provides an opportunity to advocate for incorporation of transparency initiatives within the exchange.

While additional price transparency initiatives are unlikely to be incorporated into existing contracts for plans that initially want to participate in Covered California, those initiatives could be incorporated at a later date. At this stage, the Board appears to have considerable authority to impose requirements on health plans to shape the operation of the exchange. $^{205}$ The Board did include certain reporting requirements for plans that want to participate in Covered California, but so far they largely focus on quality reporting. ${ }^{206}$ The Board should also consider similar reporting requirements for healthcare service, device, and procedure prices. However, Blue Shield of California wrote in comments to the Board that while it would favor a prohibition of anti-transparency clauses, it was too late to amend or change their contracts with providers for Qualified Health Plans, as bids were due to the exchange in January $2013 .^{207}$ If the Board is reluctant to add requirements to the initial plans, once fully established, Covered California or the California Department of Insurance, which regulates insurance

Page number(s) would have been helpful here, though I can see the section of this report devoted to technical requirements

${ }^{200}$ Id. at 70 .

${ }^{201} I d$. at 24.

${ }^{202} I d$. at 23.

${ }^{203} \mathrm{Id}$.

${ }^{204}$ California Health Benefit Exchange Vision, Mission and Values, available at http://www.healthexchange.ca.gov /Pages/HBEXVisionMissionValues.aspx.

${ }^{205}$ California Health Benefit Exchange, Qualified Health Plans Solicitation Draft 23 (Sept. 25, 2012), available at http://www.healthexchange.ca.gov/Solicitations/Documents/QHP\%20Solicitation\%20DRAFTv\%20092512public.pdf. The timeline of how the Board accepted bidders' proposals to be part of the Exchange is as follows: A first draft of the Exchange's Qualified Health Plan Solicitation Draft was released on September 25, 2012. The Board invited bidders to submit comments and suggestions by October 4, 2012. Evaluation and selection of winning bidders took place between January 7 and March 30, 2013. The negotiation of final contract terms and conditions was completed by March 31, and contracts between the Exchange and selected bidders were executed on June 1, 2013.

${ }^{206}$ Covered California, Qualified Health Plan Model Contract - First Draft (January 11, 2013), available at http://www.healthexchange.ca.gov/Solicitations/Documents/1st\%20DRAFT\%20QHP\%20Model\%20Contract\%20\% 201\%2011\%2013.pdf.

${ }^{207}$ Stakeholder Input: Qualified Health Plan Policies and Strategies to Improve Care, Prevention and Affordability, California Health Benefit Exchange (August 10, 2012). 
practices within the state, could impose additional regulations to promote price transparency on plans offered within Covered California.

The commitment to transparency in $\mathrm{AB}$ 1602, along with Covered California's position as an active purchaser, places it in an influential position to shape the ways health plans and insurance companies disclose price information to consumers on the exchange and to hold insurers accountable for meeting those requirements. But as it stands, the Board has not utilized its full authority to promote price transparency on the exchange. Evaluating current transparency initiatives employed by plans seeking inclusion in Covered California should be just the first step. To ensure consumers on the exchange have access to meaningful price and quality information in order to make educated decisions about plan selection, the Board will need to use its regulatory power to require transparency of complete cost information, like the New Hampshire and Aetna initiatives have suggested. If key stakeholders can communicate to the Board the importance of such initiatives, it may be feasible for the Board to incorporate them into Covered California in the near future. Requiring price and quality reporting as part of health plan certification on Covered California has the potential to improve consumer decision-making and spur competition in the healthcare market.

Furthermore, state exchanges may have a role to play in promoting competition and constraining the use of provider leverage to drive up costs, which in turn could promote price transparency. As ACOs move from being offered as part of the Medicare Shared Savings Program (MSSP) into the private market, the "biggest obstacle" to the ability of ACOs to obtain the triple aim of (1) better care for individuals; (2) better health for populations; and (3) slower growth in costs through improvements in care, ${ }^{208}$ is "provider market power." 209 In many ways, the introduction of ACOs into the private market "asks the private sector to respond responsibly to changes that are rife with possibilities for opportunistic behavior." 10 The vertical and horizontal integration of providers required to create an ACO will offer even more opportunities to collude on prices and obscure pricing information. "Must have" hospitals and dominant physician specialty groups that have been able to command higher reimbursement rates from private insurers are unlikely to volunteer to change the way the way they practice medicine in ways that would limit their profit margins, rather they are more likely to seek out ACO opportunities that will further entrench and expand their market power. ${ }^{211}$

In anticipation of these potential risks, CMS enlisted the cooperation of the Federal Trade Commission (FTC) and the Department of Justice (DOJ) to establish some guidelines for walking the delicate line between encouraging ACO market entry and deterring potential anticompetitive effects. The Final Statement issued by the FTC and DOJ articulates the general antitrust enforcement policies the agencies will apply to ACOs including "safety zones" for market concentration levels within common service areas, and rule of reason analysis for joint negotiations with private payers, rather than strict scrutiny. ${ }^{212}$ But many feel that these

\footnotetext{
${ }^{208}$ Donald M. Berwick, Launching Accountable Care Organizations-The Proposed Rule for the Medicare Shared Savings Program, 364 NEW ENG. J. MED. e32, e32 (2011).

${ }^{209}$ For an excellent description of the range of potential problems, See Greaney, supra note 76, at 11-24.

${ }^{210}$ Greaney, supra note 76 , at 1 .

211 Id. at 17.

${ }^{212}$ FTC \& U.S. Dep't of Justice Statement of Antitrust Enforcement Policy Regarding Accountable Care Organizations Participating in the Medicare Shared Savings Program, 76 Fed. Reg. 67,026 67,027-28. For a detailed description of the Final Statement and its antitrust implications, see Greaney, supra note 76, at 17-21.
} 
regulations do not go far enough. ${ }^{213}$ All in all, the Final Statement represents a relaxation of antitrust standards for ACOs, but as Thomas Greaney has pointed out in particular detail, of greater concern are the significant regulatory options to avoid anticompetitive behaviors that the federal government has not taken. ${ }^{214}$

Specifically, in the Final Statement, CMS, FTC, and DOJ decided to remove a condition from the Proposed Statement that would have required that all ACOs seeking certification from CMS undergo mandatory antitrust review prior to certification for participation in the MSSP. ${ }^{215}$ Such a provision would have discouraged the creation of ACOs with structural components that created opportunities for anticompetitive behaviors, and also given the antitrust agencies additional bargaining leverage in dealing with ACOs engaging in anticompetitive conduct. ${ }^{216}$ The federal agencies' bypass of stricter antitrust review and enforcement offers an opportunity for regulation at the state level, and particularly by the exchanges, to guard against further entrenchment of provider market power that drives price occlusion and increased health care costs.

\section{REGULATORY RECOMMENDATIONS}

State regulation can take many forms. First, the largest mandate a state could require would be to mandate price transparency of all plans offered by any insurer, regardless of whether the plan is offered on the exchange. Second, the exchange, through its contracting power as an active purchaser, could implement a certification process for health plans that meet more rigorous cost and quality measures. For these certified Visible Value plans, an exchange could mandate disclosure of complete price transparency, including negotiated prices to providers, by insurers to the exchange only, while allowing the exchange to publish quality and premium information to the public. This type of selective price transparency would serve to protect against over-disclosure of price information that may have unintended consequences, such as collusion, which could raise prices.

A similar model of this type of certification exists currently on the Connector, the healthcare benefit exchange in Massachusetts. The Connector screens each carrier based on a high standard of quality and rates each on a scale of one to four stars consistent with the National Committee for Quality Assurance. ${ }^{217}$ One report reviewing the Connector cautions that exchanges must strike the right balance between setting the bar too low and not effecting any change, and imposing too many requirements and running the risk of "be[ing] unable to attract a sufficient mix of the plans that consumers want."218

Additionally, an exchange board might consider creating various sub-portals within the exchange based on geographic market. A similar division of healthcare markets could also be implemented by a state Department of Insurance, which may be more equipped to determine which geographic regions would respond most positively to consumer-driven competition. ${ }^{219}$ By

\footnotetext{
${ }^{213}$ See, e.g., Greaney, supra note 76; Andrew A. Kasper, Antitrust Review of Accountable Care Organizations: An Assessment of FTC and DoJ's Relaxed Approach to Regulating Physician-Hospital Networks, 90 N.C. L.REV. 203, 236 (2011).

${ }^{214}$ Greaney, supra note 76, at 21.

${ }^{215}$ FTC/DOJ Proposed Statement, supra note XX, at 21898.

${ }^{216}$ Greaney, supra note 76, at 25.

${ }^{217}$ Sabrina Corlette et al., GeORgetown Univ. Health Policy Inst., The Massachusetts and Utah Health Insurance Exchanges: Lessons Learned 7.

${ }^{218} I d$.

${ }^{219}$ The California Department of Managed Healthcare invites public suggestions for new regulations on its website. However, information about forthcoming regulations is extremely limited. See Laws, CA.GOV,
} 
actively dividing the state into regional healthcare markets, the governing body can then choose which regions would respond best to certain transparency initiatives and only implement them in those areas. Currently, the California State Legislature has proposed such a division to partition the state into thirteen healthcare regions. ${ }^{220}$ Likewise, California's Insurance Commissioner, Dave Jones, has proposed an 18-region plan, arguing that an increased number of regions will lower possible premium increases due to the differing cost of healthcare among communities. ${ }^{221}$

Finally, exchange boards may wish to set up a portal to track which parts of the exchange website consumers visit and what they consider when choosing insurers and providers. If a board creates a price transparency initiative and wishes to track consumer traffic on its website, it should partner with healthcare economists in order to begin generating data on how healthcare consumers respond to certain initiatives in order to continue to fine-tune them.

Although the effects of regulations and statutes, so long as they are not conflicting, are similar, ${ }^{222}$ regulations serve to fast-track the above initiatives. While a board can only impact those health plans offered on the exchange, by implementing these initiatives through regulations both the board and the Department of Insurance can begin annual reviews and certifications more immediately, instead of waiting out the long and potentially futile legislative process.

\section{EMPLOYER AND CONSUMER EDUCATION INITIATIVES}

On the other hand, legal and regulatory actions are not the only potential paths. A silver lining to our country's recession and its effect on the healthcare market is that now is likely the most opportune time, on many levels, to implement price transparency initiatives. With employers increasingly shifting more healthcare costs onto their employees via high deductible health plans (HDHPs), and employees' salaries unable to keep up with the growth rate of healthcare, consumers have more incentives to be cost-conscious when purchasing healthcare products and services than ever before. With consumers paying closer attention to healthcare prices, and providers, in turn, taking notice of consumer healthcare trends, ${ }^{223}$ both employers and consumers are poised to be target audiences for price transparency initiatives.

\section{CONSUMER-LEVEL INITIATIVES}

Targeting consumers directly with price transparency initiatives will be harder and may prove least effective of all possible avenues in lowering healthcare prices overall. Pricing information varies from consumer to consumer based on insurance carrier, type of health plan, and geographic location. Further, not all price information will be relevant to all consumers. This means that effecting change on a consumer level will require disclosing price information on a variety of levels to incorporate all the necessary variables to influence enough consumers to make a difference in healthcare spending. Creating and designing an initiative that would allow

\footnotetext{
http://www.dmhc.ca.gov/aboutthedmhc/law/

law_default.aspx (last visited Oct. 22, 2012).

${ }^{220}$ A.B. X1-2 \$10753.14(A)(2), 2013-2014 Sess. (Ca. 2013), available at

http://leginfo.legislature.ca.gov/faces/billNavClient.xhtml?bill_id=201320141AB2.

${ }^{221}$ Insurance Commissioner Jones issues statement to oppose geographic rating proposals that would result in rate increases for California healthcare consumers, CALIFORNIA DEPT. OF INS., available at

http://www.insurance.ca.gov/0400-news/0100-press-releases/2013/upload/statement017HernandezLtr.pdf.

${ }^{222}$ Violations of both regulations and laws can result in similar penalties and fines.

${ }^{223}$ COMMONWEALTH OF MASSACHUSETTS, RECOMMENDATIONS OF THE SPECIAL COMMISSION ON PROVIDER PRICE REFORM 13 (Nov. 9, 2011) (reporting that "the use of differential employee health insurance contributions based on provider cost and quality" in Maine and Minnesota led to 100\% of Maine hospitals reporting quality data and Minnesota providers strengthening their credentials in direct employer contracting and improving coordination and joint decision making among hospitals and physicians), available at http://www.mass.gov/chia/docs/g/pr/special-comm-ppr-report.pdf.
} 
consumers to retrieve specified price information based on several variables would cost more than simply mandating that providers disclose their negotiated reimbursement rates. It would require gathering those rates for each provider and insurer contract, as well as quality measures from each provider, and distilling that information into streamlined figures that can be manipulated through an Internet portal to compare such variables by insurer, health plan, location, and budget.

The next step in disclosing healthcare costs to consumers is ensuring usability of that information. As they currently exist, hospital billing codes, methods of healthcare service bundling, and the various levels of cost-shifting (from numerous providers, to insurers, to employers) make comprehension of healthcare pricing extremely difficult for the average consumer. $^{224}$ But given the trend of enrollment in HDHPs, a growing number of consumers are poised to start paying more attention to healthcare expenditures. Although there is still no guarantee consumers will use available cost and quality information when purchasing health insurance or choosing a provider, there are certain ways of presenting more meaningful cost information that will serve to educate consumers. Also, a younger generation of healthcare consumers may be more familiar with and willing to use these kinds of online tools to evaluate health plan and provider options.

For any generation, the more meaningful transparency information is to consumers, the more likely it is to influence their healthcare decision-making. Separate disclosure of price and quality information, as is typical, is too fragmented to be useful for consumers. ${ }^{225}$ Rather, presenting cost and quality information either in a side-by-side comparison or a separate scale that is easy to understand may inspire healthcare consumers to act more like consumers in other markets, resulting in lower overall healthcare costs. ${ }^{226}$

One solution to promoting usability of transparency information is to develop a website that enables consumers to enter their health plan, medical condition, and geographic location to generate a list of available providers and their prices and quality scores. This initiative would require higher start-up costs than other price transparency measures. For instance, it would likely require the development of software to convert thousands of healthcare products and services, at thousands of facilities, into one state-wide scale of measurement. This initiative, however, is a prime example of a model that may qualify for demonstration grant funding under the ACA, which could alleviate state implementation costs. ${ }^{227}$ If consumers begin to use this information in large numbers to choose lower cost providers, which remains a significant question, they could reduce provider leverage and healthcare costs overall.

\section{EMPLOYER-LEVEL INITIATIVES}

Higher spending for hospital, physician, and other clinical services accounted for over 80 percent of premium increases between 2005 and 2009. ${ }^{228}$ As it stands, employer demand for broad provider networks gives providers substantial leverage to contract for higher prices with insurers in order to participate in their network. In a market with substantial provider leverage for

\footnotetext{
${ }^{224}$ CRS REPORT FOR CONGRESS, supra note 9, at 4, 8, 10.

${ }^{225}$ Hibbard \& Peters, supra note 38, at 415-16.

${ }^{226}$ See Reinhardt, supra note 15, at 66-67 (stating also that he proposed a similar hospital rating system for consumers in 1993 that allowed each hospital to maintain their own quality and pricing measurements while assigning each a conversion factor, allowing for a national body of experts to calculate each hospital's cost and quality measures on the same "weight scale").

${ }^{227}$ Patient Protection and Affordable Care Act, supra note 218.

${ }^{228}$ Julie A. SCHOENMAN \& NANCY CHOCKLEY, NAT'L INST. FOR HEALTH CARE MGMT. Found., Understanding U.S. Health Care Spending (2011), 9-10, available at http://nihcm.org/images/stories/NIHCM-CostBrief-Email.pdf.
} 
"must-have providers", transparency initiatives could cause insurers to pay more for all provider groups, if they reveal that they pay higher prices to dominant providers. ${ }^{229}$ Once exposed, it is more likely that other providers will also demand higher prices, rather than the "must-have provider" reducing their prices. Insurers can regain leverage by convincing employers to shift their preferences to narrower, but high quality, networks. With provider payment and quality information transparent to employers, employers would then have the tools and knowledge to demand plans that offer particular low-cost, high-quality providers. This would allow employers to save money on healthcare benefits and, at the same time, to offer employees greater value healthcare.

Narrow and tiered networks have already gained some traction in the small group market, especially when combined with consumer-driven health plans, such as HDHPs. ${ }^{230}$ For example, in Indianapolis, where consumer-driven health plan enrollment is high, health plans focus on helping employers see the benefits of choosing those plans that incorporate lower-cost, highquality services, thereby narrowing the network of providers needed on a given health plan. ${ }^{231}$ By educating employers about the value of certain providers, insurers are not only saving money themselves, but they also help employers save money on healthcare costs and provide better value care for their employees. Unfortunately, this strategy has been circumvented by the manipulation of billing codes, whereby providers attempt to convolute insurers' ability to determine which facilities provide lower-cost services. ${ }^{232}$ To thwart this potential barrier it will be necessary, as mentioned in Section IV.C.3, to demystify billing codes for employers as well as individual consumers.

Consumer-driven plans not only incentivize individual consumers to stay healthy, but also change the nature of the healthcare market. In theory, consumers enrolled in HDHPs will pay closer attention to the cost of their day-to-day healthcare than those on traditional health plans with copays. Since enrollees of consumer-driven health plans have incentives to be costconscious consumers, efforts to introduce employer-level transparency and to educate both employers and consumer would allow employers to choose health plans with smaller networks of high-quality, lower-cost providers and communicate those better value plans to their employees. This employer-based strategy will prove most effective at reducing healthcare costs in geographic markets with a wide range of choices among physicians and hospitals, because it will increase transparency and, therefore, competition among providers to be recognized as lowercost, high-quality providers that employers should want to direct their employees toward. This type of initiative will prove less effective in markets with provider monopolies or few competitors.

Shifting the leverage from providers to employers (and individual consumers) may also yield particularly beneficial results in the self-insured employer arena. In order to educate employers about the potential cost-saving power of a price transparency initiative, it is likely that human resources departments, insurance brokers, and private companies, like Castlight Health

\footnotetext{
${ }^{229}$ Berenson, et al., supra note 24, at 977.

${ }^{230}$ Christianson, et al., supra note 3129, at 3 (stating that narrow networks may work better to restrict physician networks over hospitals, because those with negotiating leverage can avoid being placed in a less-preferred tier or excluded from narrow networks).

${ }^{231} I d$. at 4 (stating that, in addition to insurers in the Indianapolis market, BlueCross BlueShield in Syracuse has reduced growth in high-cost imaging by requiring prior-authorization for high-cost imaging centers). ${ }^{232} I d$.
} 
will need to play a role in helping employers understand their options. ${ }^{233}$ For instance, Castlight creates an online space where employees of self-insured employers can shop for healthcare based on price, quality and how much of their deductible is already spent. By educating employers about how to, in turn, educate their employees, data gathered by Castlight demonstrates that helping self-insured employers aid their employees in informed healthcare decision-making can change employee behavior. ${ }^{234}$ As the main purchasers of healthcare, employers should exercise some leverage of their own. If large companies demanded price transparency, whether through an intermediary such as Castlight or on their own, providers who once were able to leverage higher prices against blind employers would either need to produce evidence of value or else accept lower payments.

To realize this change, self-insured employers may negotiate lower prices in exchange for incentivizing employees to use the provider, as Lowe's Company has done with the Cleveland Clinic. $^{235}$ The North Carolina-based company encourages its employees from all across the country to travel to the Cleveland Clinic for high quality heart procedures at comparatively low prices. $^{236}$ Because of the size of Lowe's employee base, the arrangement was beneficial enough for Lowe's that it agreed to pay for all travel and lodging costs for employee-patients and a companion, as well as waive a $\$ 500$ deductible, among other out-of-pocket costs. ${ }^{237}$ Through employer initiative and innovation, Lowe's is able to offer better quality healthcare to its employees at a lower cost. If more self-insured employers can demand services, compare the cost and quality of healthcare nationwide, and incentivize employees to seek out recommended providers, not only may employers realize savings, but individual consumers may also see the effects of transparency on their costs as well. For example, it may be difficult for providers to continue demanding higher payments for individual consumers when their prices and quality information, now transparent to employer-consumers, suggest services are worth less.

\section{AnTitrust SOLUTIONS}

As discussed above, dominant providers and insurers can use their market power as leverage to drive up healthcare prices and conceal the increases from employers and consumers. While antitrust regulation offers a potential path to address anticompetitive behaviors going forward, antitrust litigation offers a way to break down existing market power by protecting consumers-not competitors-from anticompetitive actions in the marketplace. ${ }^{238}$ Because the healthcare market is rife with market inefficiencies, ${ }^{239}$ dominant parties in healthcare are especially able to leverage their market power and thereby make wealth distributions even more

\footnotetext{
${ }^{233}$ The Massachusetts Connector actually requires that one of its Board members be an insurance broker. CORLETTE ET AL., supra note 217, at 5.

${ }^{234}$ CASTLIGHT HEALTH, http://www.castlighthealth.com/why-castlight (last visited Oct. 22, 2012) (reporting that Castlight Health has helped customers achieve $870 \%$ employee engagement rates; that $61 \%$ of employees made medical care decisions based on Castlight's recommendations, resulting in a $13 \%$ reduction in spending and $38 \%$ improved care; and that Castlight users are $40 \%$ less likely to go out-of-network for healthcare).

${ }^{235}$ Havighurst \& Richman, supra note 202, at 877 n. 89.

${ }^{236}$ Id.; see also Harlan Spector, Lowe's-Cleveland Clinic Deal Could Be a Model for Health-Care Reform Through Competition: A Medical Checkup Column, CLEVELAND.COM (Mar. 2, 2010), http://www.cleveland.com/healthfit/ index.ssf/2010/03/lowes-cleveland_clinic_deal_co.html (explaining that Lowe's Company analyzed five separate heart centers before striking the deal with the Cleveland Clinic).

${ }^{237}$ Id. (citing Harlan Spector, Lowe's Will Bring Its Workers to Cleveland Clinic for Heart Surgery, CLEVELAND.COM (Feb. 17, 2010), http://www.cleveland.com/healthfit/index.ssf/2010/02/post_27.html).

${ }^{238}$ See ROBERT BORK, THE ANTITRUST PARADOX 51 (1978).

${ }^{239}$ See supra Part II.
} 
lopsided, which contributes to the high price variation between hospitals. ${ }^{240}$ In combination with price transparency and antitrust legislation or regulation governing health care providers, an antitrust suit can help force dominant parties to reveal their competitive prices by making market conditions more responsive to changes in consumer demand. This section will analyze three potential avenues for bringing an antitrust suit to promote price transparency.

\section{Contractual PROVISIONS BETWEEN PROVIDERS AND PAYERS}

The Sherman Act is the primary vehicle for U.S. antitrust enforcement. ${ }^{241}$ Section One of the Sherman Act prohibits multiple parties from engaging in a "contract, combination, or conspiracy" that constitutes an unreasonable restraint of trade. ${ }^{242}$ To prove a Section One violation, a plaintiff must prove the existence of a multi-party agreement ${ }^{243}$ and that the agreement is an unreasonable restraint. ${ }^{244}$

Certain contract provisions between providers and insurers may constitute unlawful contracts under Section One. Most notably, most favored nation ("MFN") clauses that guarantee insurers they are receiving a provider's best rates - a form of payment parity agreement-open the door for antitrust liability by limiting the prices that providers can charge to other insurers. MFN clauses can harm competition by locking in payment levels, thwarting innovation, and preventing price competition. ${ }^{245}$ In addition, agreeing to an MFN clause causes providers to lose any incentive to offer lower prices, because they must offer the same low price to all insurers, which results in an increased equilibrium price throughout the market. ${ }^{246}$

MFN challenges are commonly brought against dominant insurers, as in the case of the Department of Justice's challenge to Blue Cross Blue Shield in Michigan, which dominates the Michigan insurance market with anywhere from $40 \%$ to $80 \%$ market share across different geographic areas. ${ }^{247}$ Establishing liability under this theory would require evidence that insurers have used MFN clauses to force providers to charge competing insurers higher rates, thereby unreasonably restraining trade. Despite the anticompetitive harms caused by the enforcement of MFN clauses, however, it is unclear what the impact of such a suit would be on price transparency. Furthermore, the strongest MFN suit would challenge dominant insurers, but the

\footnotetext{
${ }^{240}$ See, e.g., Berenson et al., supra note 24, at 2; Peter Waldman, Sutter Health's Market Power Is Questioned, BLOOMBERG BUSINESSWEEK (Aug. 26, 2010), http://www.businessweek.com/magazine/content/10_36/b419301598 3853.htm.

${ }^{241}$ The Federal Trade Commission Act and the Clayton Act also govern U.S. antitrust law.

${ }^{242}$ Sherman Antitrust Act of 1890, 15 U.S.C. $\S 1$. Section Two of the Sherman Act deals with single-firm monopolies, see 15 U.S.C. $\S 2$, but, importantly, a monopoly is not unlawful if it was acquired by "skill, foresight and industry." United States v. Aluminum Co. of Am., 148 F.2d 416, 430 (2d Cir. 1945). Likewise, an attempted monopolization claim requires "predatory" conduct, "specific intent to monopolize," and a "dangerous probability" that the party will succeed in foreclosing competition. Spectrum Sports v. McQuillan, 506 U.S. 447, 456 (1993).

${ }^{243}$ It is crucial that there be two parties, because a single party cannot make an unlawful agreement with itself. See United States v. Colgate \& Co., 250 U.S. 300, 307 (1919).

${ }^{244}$ For an agreement to be an unreasonable restraint of trade, either the two parties must be competitors or the agreement must directly affect others in the market. In the context of healthcare, this means that certain agreements between insurers and providers do not constitute unreasonable restraints of trade, because they do not directly impact competition. See, e.g., Royal Drug Co. v. Group Life \& Health Ins. Co., 737 F.2d 1433 (5th Cir. 1984).

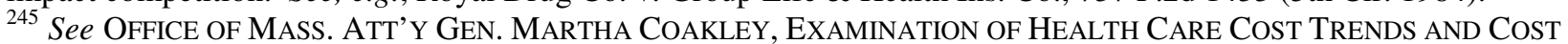
DRIVERS PURSUANT TO G.L.C. 118G, $\S 61 \frac{1}{2}(\mathrm{~b}), \quad 35$ at $40-41$ (2010), available at http://www.mass.gov/ago/docs/healthcare/2011-hcctd-full.pdfhttp://www.mass.gov/ago/docs/ healthcare/final-report-w-cover-appendices-glossary.pdf.

${ }^{246}$ See Fiona SCOTT-Morton, DOJ, CONTRACTS THAT REFERENCE Rivals 12(Apr. 5, 2012).

${ }^{247}$ See Complaint, United States v. Blue Cross Blue Shield of Mich., No.2:10-cv-14155-DPH-MKM (E.D. Mich. Oct. 18, 2010).
} 
economic literature suggests that dominant providers are more of a problem in keeping prices hidden from consumers. ${ }^{248}$ Breaking down dominant insurers' market power may also make them less powerful negotiators to challenge these providers. Thus, while such a lawsuit might have some success in breaking down entrenched market power, it may not be the best route to achieve price transparency.

\section{TYING ARRANGEMENTS}

Another theory of antitrust liability under Section One is unlawful tying, which occurs when a company uses its market power in one product to coerce the purchase of a second, separate product. ${ }^{249}$ To prove a tie, there must be (1) two separate products involved, (2) a tie requiring the purchase of the tied product as a condition of buying the tying product, (3) sufficient market power in the tying product to make the coercion possible, and (4) a not insubstantial effect on interstate commerce in the tied product's market. ${ }^{250}$ A party is harmed by and therefore has standing to challenge an illegal tying arrangement if it is either a purchaser forced to buy the tied product or a competitor prevented from competing in the tied product's market as a result of the illegal tie. ${ }^{251}$

\section{a. Unbundling Services}

One potentially unlawful tie in the healthcare market is hospitals' bundling of services in their negotiations with payers, which effectively masks the prices of individual services. Litigation would address hospitals' conditioning of insurers' purchase of services in which they have market power (the tying product) on the purchase of distinct, non-dominant services (the tied product). For instance, if a hospital offered the only neurosurgery department in a metropolitan area, it could require an insurer to pay a single high price for all services provided at the hospital in order to include the hospital's neurosurgery services in its network. Forcing the separation of those services that are not functionally related will reveal the discrete values of each service, thus enabling insurers to negotiate for the true value of each service and therefore set more efficient prices for consumers. For consumers willing to accept narrower networks, this would allow for the creation of health plans that offer greater value for cost. ${ }^{252}$ This theory of tying, however, might face difficulty in court due to the perceived and actual benefits of bundling services, ${ }^{253}$ but with careful analysis of the impact on consumers, the availability of alternatives, and the ease of entry into the market, appropriately tailored antitrust litigation could help break apart distinct services. A price transparency initiative could then provide consumers with accurate information about those services.

\section{b. Breaking Geographic Ties}

A second possible incidence of unlawful tying exists in the practice of dominant hospital networks abusing their market power in one geographic market (the tying product) to coerce insurers to purchase their services in other geographic locations (the tied product). Insurers have highlighted this concern, pointing to provider networks that span several geographic markets and

\footnotetext{
${ }^{248}$ See, e.g., Berenson et al., supra note 24, at 974.

249 Times-Picayune Publ'g Co. v. United States, 345 U.S. 594, 605 (1953).

${ }^{250}$ Fed. Trade ComM'N \& DeP'T OF Justice, IMPRoving HeAlth CARE: A Dose Of Competition 99 (July 2004); see also Eastman Kodak Co. v. Image Technical Servs., Inc., 504 U.S. 451 (1992); Jefferson Parish Hosp. Dist. No. 2 v. Hyde, 466 U.S. 2 (1984).

${ }^{251}$ Abraham v. Intermountain Health Care Inc., 461 F.3d 1249, 1266 (10th Cir. 2006).

252 See Clark C. Havighurst \& Barak D. Richman, The Provider Monopoly Problem in Health Care, 89 OR. L. REV. 847, 877 (2011).

${ }^{253}$ Stephanie Alessi, Using Antitrust Law to Increase Efficiency in the Healthcare Market (2013) (on file with authors).
} 
insist health plans contract with them on an "all-or-nothing" basis, ${ }^{254}$ thereby allowing providers to increase rates and impose non-price requirements that prevent cost-containment and transparency. ${ }^{255}$ To date, a claim of geographic tying has not been alleged and therefore would have to overcome many legal hurdles, but because of the tendency of these ties to harm competition, courts may be willing to apply antitrust liability to this conduct under a theory of tying.

Most notably, of the four elements of an unlawful tie, proving the existence of two separate products will be difficult. Patient demand for services in distinct geographic regions may demonstrate that two hospitals in one network satisfy the separate products test, ${ }^{256}$ but the case law is unclear as to whether an unlawful tie can exist where the two products are part of the same network but in different geographic markets. ${ }^{257}$ Although this argument aligns with the general justifications for prohibiting tying, ${ }^{258}$ a court may be unwilling to distinguish between separate products offered by a single hospital network that operates as a single company and negotiates on a broad geographic scale. Furthermore, establishing the second element, the existence of a coercive tie, requires proof that the tie coerced the insurer to purchase the tied product; that is, if the insurer might have contracted with the hospital in the tied market notwithstanding the tie - the difference being only the amount it paid — there might be a strong argument against the establishment of antitrust liability. ${ }^{259}$ Finally, the last two elements of the claim-market power and foreclosure of a substantial amount of competition-both require intensive economic analysis, including analysis of market share and barriers to entry in the primary market, as well as procompetitive and anticompetitive effects in the secondary market. ${ }^{260}$ If these elements can be proven, challenging these geographic ties has the potential to break up market power and force providers to negotiate rates separately for their services in each geographic region.

When paired with price transparency, breaking these ties should enable insurers to negotiate competitive rates and, in turn, allow employers and consumers to engage more fully with the healthcare marketplace. Specifically, if hospital networks are forced to negotiate rates that reflect the products they are offering in the immediate geographic region-without the added leverage of a distant must-have provider-they should no longer be able to maintain anticompetitive, artificially high rates after the ties are broken. In geographic regions where

\footnotetext{
${ }^{254}$ Berenson et al., supra note 24 , at 974 ; id. at 978-79 ("[A] leading form of consolidation is the multihospital system extending across large geographic areas, which in most cases does not lead to antitrust scrutiny."); Letter from Blue Shield of California to Federal Trade Commission dated May 27, 2011, at 3.

${ }^{255}$ Letter from Blue Shield of California to Federal Trade Commission dated May 27, 2011, at 4; see also RECOMMENDATIONS OF THE SPECIAL COMMISSION ON PROVIDER PRice ReForm 25 (Nov. 9, 2011).

${ }^{256}$ See Jefferson Parish, 466 U.S. 2 at 21-22; see also Alessi, supra note 203 (describing the Court's interpretation of the separate products test).

${ }^{257}$ Alessi, supra note 203

${ }^{258}$ Tying arrangements are forbidden because "[t]hey deny competitors free access to the market for the tied product .... [and] buyers are forced to forego their free choice between competing products." N. Pac. Ry. Co. v. United States, 356 U.S. 1, 6 (1958).

${ }^{259}$ Alessi, supra note 203. In certain metropolitan areas, studies of provider-insurer negotiations have shown that hospital networks that include a dominant hospital exercise significant leverage over insurers; Berenson et al., supra note 24193, at 974.

${ }^{260}$ Alessi, supra note 203. Pro-competitive effects might include the fact that hospital networks enable an entire network of hospitals to negotiate together and the efficiency and quality benefits of an integrated system. Berenson et al., supra note 24193, at 975-9764-5. Anticompetitive effects include the stifling of the negotiation process and the resulting inability to set market-rate prices for distinct services. Alessi, supra note 203.
} 
hospital networks lack leverage in the form of must-have providers, the public release of price and quality information would give insurers and consumers sufficient information to arrive at efficient market solutions in rate negotiations and purchasing decisions, respectively. Thus, a price transparency mandate that follows successful geographic-tie-breaking antitrust litigation could be highly beneficial to consumers, at least in certain regions. In regions where networks include must-have providers, however, those networks would likely maintain their market power and ability to maintain high prices. There, a price transparency mandate could result in a parallel price increase across providers who would now have full access to the rates their competitors were receiving, allowing them to raise their rates to the same level. ${ }^{261}$ Consequently, even if antitrust litigation is successful in breaking apart geographic ties, the benefits of any price transparency regulation targeted at regions with the added leverage of a must-have provider must be carefully weighed against the potential of causing other providers to increase their prices.

\section{ANTITRUST OVERVIEW AND REQUISITE FACT-GATHERING}

Any of these options will first require gathering facts about the markets, competition, and contracts at issue. Important evidence to gather will include: contract terms that might constitute unreasonable restraints; the impact of contract provisions on competition; accurate measures of market power; economic analysis of product and geographic markets; and measures of the impact on competition caused by the alleged unlawful agreements.

In considering whether litigation would be worthwhile, it is also important to consider whether the remedy will be simply an injunction or treble damages and what the deterrent effect of that remedy would be, both on the specific entity against whom the case were brought and as a more general deterrent. To change widespread behavior, antitrust enforcement is costly and uncertain, but simply targeting a small number of dominant parties would demonstrate the state's willingness to challenge anticompetitive behavior and discourage other provider organizations from abusing market leverage.

\section{RECOMMENDATIONS}

The most effective combinations of these solutions will include two elements: (1) one that targets provider leverage by discouraging anticompetitive behavior, and (2) another that mandates disclosure of price information. For instance, breaking apart geographic markets, alone, risks only reforming healthcare pricing in the select areas where geographic ties exist. On the other hand, merely requiring price transparency may have the unwanted result of driving up healthcare costs in some markets. In combination, however, these elements have the potential to effectively lower healthcare costs across each state. There are multiple different methods for combining these two elements, which are discussed below.

\section{A. "Visible VALUE" STANDARD CERTIFICATION}

Certification of health plans under the "Visible Value" standard through administrative or legislative action also has the ability to dismantle geographic tying and implement price transparency. The Visible Value standard would be a set of criteria created by a state exchange or Department of Insurance whereby health plans could voluntarily submit cost, quality, and anticompetitive activities data to the exchange in order to apply for certification. The exchange would then list these criteria on its website and indicate which plans on the exchange were certified under this standard.

To receive certification, a health plan would need to meet three conditions. First, the exchange boards, or other government agencies, would determine a plan's best-value criteria by

\footnotetext{
${ }^{261}$ See, e.g., supra Part IV A and accompanying notes and text.
} 
evaluating the price and quality measures of each plan. This data could be collected entirely by voluntary disclosure from each health plan as part of the application process. Second, a health plan must demonstrate it is not a product of any anticompetitive tactics, such as geographic tying leverage. This may incentivize providers to refrain from anticompetitive activities in order to be included in a Visible Value standard health plan. Third, a certified health plan must show that provider reimbursement rates are based on value-based payment systems, rather than on a feefor-service basis. These three conditions, along with the subsequent criteria, could be made transparent to consumers via publication on a state exchange website. With the proper consumer education, this initiative not only incentivizes health plans to meet these best-value standards, but also has the benefit of helping to usher consumers toward these plans.

Through these mandated disclosures, the certification process stands to provide states with health plans of great value and integrity. If a large number of consumers purchase Visible Value standard plans, more insurer-provider partnerships may be motivated to follow suit.

\section{B. EMPLOYER-LED LEVERAGE FLIP}

Taking a market-based approach, a second solution would use education initiatives to inform employer healthcare purchasing incentives. This strategy would encourage employers to exercise their leverage as purchasers and demand price transparency from providers and insurers. In geographic markets where consumers have a wide range of choices among physicians and hospitals, initiatives to improve education and make information more widely available would empower healthcare purchasers to force sellers to compete with one another in the market. In those markets where price transparency is most likely to be effective, this strategy would enable employers to demand the price and quality information they need. In contrast, markets with fewer competing parties would see minimal effects from employer-driven demand for transparency and thus should not be targeted.

Education initiatives should focus on making human resources departments aware of the potential cost savings they can achieve by highlighting and incentivizing lower-cost healthcare options for their employees and offering narrower and more efficient provider networks. Healthcare consumers have grown increasingly cost-conscious in recent years, ${ }^{262}$ so they are more likely to be responsive to financial incentives. By encouraging employers to demand smaller, high-value provider networks, it is possible to harness this cost-awareness and thereby give the employer-purchasers of healthcare an increasing amount of bargaining power against dominant sellers. Self-insured employers are in a particularly good position to lower their costs in this way by encouraging their employees to make more efficient healthcare purchasing decisions in exchange for lower premiums and out of pocket expenses.

To make these initiatives most effective, the analysis of, and education about, healthcare options should be driven by a multi-stakeholder organization. Including representatives from business, provider, insurer, and consumer groups can ensure an even-handed analysis of healthcare value that fully considers all perspectives and potential costs and benefits. Once appropriately informed with objective information, employers could use their new power as fully informed purchasers to match the negotiating leverage of providers and insurers. Consequently, dominant parties would be less able to hide price information or engage in other anticompetitive tactics like tying the purchase of their services in one market to those in other markets.

\section{HeAlthCARE MARKet Regions}

\footnotetext{
${ }^{262}$ See supra Part VI.D.I.
} 
A third mechanism for implementing both necessary elements is promulgating regulation through the State Department of Insurance or similar government agency to divide the state into independent healthcare regions and, simultaneously, mandate price transparency in the more competitive regions. The independent regions would represent distinct product markets that would prevent dominant providers from abusing their market power in one market by coercing the purchase of their services in another. Unlike the difficulty of proving distinct markets posed by antitrust litigation, ${ }^{263}$ this regulatory initiative would clearly outline each region, eliminating providers' defense that they are merely selling services in a single, state-wide market. The creation of the regions would serve to eliminate the existing geographic ties among regions, thereby breaking up market power and forcing providers to negotiate rates for their distinct geographic services. ${ }^{264}$

The Dartmouth Healthcare Atlas has established regional healthcare divisions throughout the United States and currently collects data on a wide range of factors for Medicare patients living in each region. ${ }^{265}$ A state could either use the regions created by the Atlas or set up its own regional division of healthcare communities. While we recommend splitting these regions further into smaller markets, some markets, such as that for organ transplantation, would necessarily extend beyond regional boundaries depending on certain healthcare services offered. Therefore it will be important to specify services when arranging these geographic markets.

The division of a state into separate healthcare markets should be done in a manner to satisfy the antitrust requirements for defining a geographic market, such that buyers would be unable to switch to alternative sellers in sufficient numbers to defeat an exercise of market power by firms in the area. ${ }^{266}$ Further, healthcare delivery and other data collected could be reviewed regularly to track market power abuses.

The second half of the regulation would mandate disclosure of healthcare price information negotiated by insurers and providers. However, the law would require price transparency only in those regions where "must-have" providers and providers supplying unique services within that market cannot use excessive leverage to demand higher costs. ${ }^{267}$ Mandated price transparency in regions with great provider leverage may result in a rise in healthcare costs to consumers. As a result, it will be important to first identify those regions where transparent pricing information would most likely result in lower healthcare costs, and mandate that insurers and providers reveal their negotiated prices in those regions. A mechanism for monitoring each region by a government entity such as the Department of Insurance may be necessary to determine which regions will require these regulations in the future. For added enforcement, the regulation should also include a provision for regulatory sanctions and alert providers to the possibility of antitrust litigation.

Although not as precise as a geographic tying claim in an antitrust lawsuit, the creation of distinct geographic regions can weaken market coercion when accompanied by price transparency initiatives in those regions most receptive to the positive effects of market competition.

\footnotetext{
${ }^{263}$ See supra Part V.A.5.d; see also Alessi, supra note 203 (arguing that one of the most significant hurdles to establishing a geographic tying claim would be proving that separate geographic markets served by a single hospital network constitute distinct product markets capable of being tied together).

264 This regulation may not, however, prevent providers from tying services between submarkets.

${ }^{265}$ Data by Region, DARTMOUTH ATLAS OF HEALTH CARE, http://www.dartmouthatlas.org/data/region (last visited Nov. 6, 2012).

${ }^{266}$ Hospital Corporation of America, 106 F.T.C. 361 (1985).

${ }^{267}$ See supra Part V.B.
} 


\section{ANTITRUST LitigATION AND LEGISLATION/REGULATION}

The combination of bringing an antitrust suit to break apart and prevent anticompetitive tying and passing legislation or regulation to mandate price transparency has the potential to reduce costs through improving competition. Simultaneously requiring price transparency and reducing anticompetitive behavior could make prices both visible and fair. The antitrust suit would likely challenge providers' higher prices derived from anticompetitive ties linking geographic markets and/or unrelated services. ${ }^{268}$ Even the specter of a successful suit could reduce provider willingness to leverage their power to demand uncompetitive prices.

For this approach to work, antitrust litigation must take place prior to legislative or regulatory change. Although transparent prices would allow the Attorney General to use discovery to gather useful data to inform an antitrust suit, because of the uncertain outcomes of enacting price transparency alone in regions where providers or insurers have substantial leverage ${ }^{269}$ the first step in this process should be using antitrust litigation to break down and discourage anticompetitive uses of market leverage. ${ }^{270}$ The results of the lawsuit could then be used to drive support for potential legislation or regulation.

Despite the potential benefits of this combination of antitrust litigation and legislative or regulatory change, there is a high risk of failure. The antitrust lawsuit may fail at a number of stages: The given Attorney General may not be interested in prosecuting the case; the court may reject the geographic tying claim; ${ }^{271}$ or the lawsuit may fail for a number of other reasons, including the inability to obtain price information due to its trade secret status or to gather other requisite facts to establish liability. Notably, filing an antitrust lawsuit does not guarantee the disclosure of healthcare pricing information during discovery, particularly if that information is under a protective order to preserve its confidentiality. ${ }^{272}$ This may prove to be a substantial obstacle. Even if the antitrust suit does succeed, which could take a number of years, it may be difficult to achieve the hoped-for legislative or regulatory measures to make prices transparent in a meaningful way. Therefore, although this combination has great potential to benefit consumers, these contingencies suggest the benefits may not be easy to obtain even with a significant investment in data collection. In the end, this approach requires a substantial investment of time, money, and manpower, with uncertain prospects for success.

\section{CONCLUSION}

The above recommendations combine the breaking apart of geographic regions and the requirement of price transparency to create an effective attack on rising healthcare prices. In addition to each of these recommendations, other solutions discussed in Section VII could also be implemented separately to further ensure the greatest level of success. The first of these two solutions is stringent evaluation of all insurance premium increases of $5 \%$ or more by the Department of Insurance. The second solution is the implementation of consumer-education initiatives. The most important aspect of any price transparency initiative will be the education provided to employers and consumers about the newly available price and quality information. Without an understanding of how this information can help each group make more informed healthcare decisions and save on healthcare costs, simply making prices and quality scores

\footnotetext{
268 Alessi, supra note 203.

${ }^{269}$ See supra Part II.

270 Alessi, supra note 203.

${ }^{271}$ See supra Part V.A.3.b; see also Alessi, supra note 203.

${ }^{272}$ See supra Parts III.A \& B.
} 
available to the public will not have the desired effect of lowering the cost of healthcare. But, by providing employers and consumers with meaningful and transparent information about their healthcare choices and ensuring that those choices are not exploitative, a well-crafted price transparency initiative can begin to reduce the inefficiencies that characterize the healthcare market and make healthcare more affordable. 
